\title{
UV Irradiation and Near Infrared Characterization of Laboratory Mars Soil Analog Samples: the case of Phthalic Acid, Adenosine 5'- Monophosphate, L-Glutamic Acid and L-Phenylalanine Adsorbed onto the Clay Mineral Montmorillonite in the presence of Magnesium Perchlorate
}

\author{
Teresa Fornaro $^{1,2^{*}}$, John R. Brucato ${ }^{1}$, Giovanni Poggiali ${ }^{1,3}$, Maria Angela Corazzi ${ }^{1,3}$, \\ Malgorzata Biczysko ${ }^{4}$, Maguy Jaber ${ }^{5}$, Dionysis I. Foustoukos ${ }^{2}$, Robert M. Hazen², Andrew \\ Steele $^{2}$ \\ ${ }^{1}$ INAF-Astrophysical Observatory of Arcetri, Florence, Italy \\ ${ }^{2}$ Earth and Planets Laboratory, Carnegie Institution for Science, Washington, DC, USA \\ ${ }^{3}$ Department of Physics and Astronomy, University of Florence, Florence, Italy \\ ${ }^{4}$ International Centre for Quantum and Molecular Structures, Physics Department, College of \\ Science, Shanghai University, Shanghai, China \\ ${ }^{5}$ Laboratoire d'Archéologie Moléculaire et Structurale, Sorbonne Université, Paris, France
}

\section{* Correspondence:}

Teresa Fornaro

teresa.fornaro@inaf.it

Keywords: molecular biosignatures, Mars, UV irradiation, infrared spectroscopy, life detection.

\begin{abstract}
The search for molecular biosignatures at the surface of Mars is complicated by an intense irradiation in the mid- and near- ultraviolet (UV) spectral range for several reasons: (i) many astrobiologically relevant molecules are electronically excited by efficient absorption of UV radiation and rapidly undergo photochemical reactions; (ii) even though the penetration depth of UV radiation is limited, aeolian erosion continually exposes fresh material to radiation; and (iii) UV irradiation generates strong oxidants such as perchlorates that can penetrate deep into soils and cause subsurface oxidative degradation of organics.

As a consequence, it is crucial to investigate the effects of UV radiation on organic molecules embedded in mineral matrices mimicking the martian soil, in order to validate hypotheses about the nature of the organic compounds detected so far at the surface of Mars by the Curiosity rover, as well as organics that will be possibly found by the next rover missions Mars 2020 and ExoMars 2020. In addition, studying the alteration of possible molecular biosignatures in the martian environment will help to redefine the molecular targets for life detection missions and devise suitable detection methods.

Here we report the results of mid-UV irradiation experiments of Mars soil analog samples obtained adsorbing relevant organic molecules on a clay mineral that is quite common on Mars, i.e. montmorillonite, doped with $1 \mathrm{wt} \%$ of magnesium perchlorate. Specifically, we chose to investigate
\end{abstract}


the photostability of a plausible precursor of the chlorohydrocarbons detected on Mars by the Curiosity rover, namely phthalic acid, along with the biomarkers of extant life L-phenylalanine and L-glutamic acid, which are proteomic amino acids, and adenosine 5'-monophosphate, which is a nucleic acid component.

We monitored the degradation of these molecules adsorbed on montmorillonite through in situ spectroscopic analysis, investigating the reflectance properties of the samples in the Near InfraRed (NIR) spectral region.

Such spectroscopic characterization of molecular alteration products provides support for two upcoming robotic missions to Mars that will employ NIR spectroscopy to look for molecular biosignatures, through the instruments SuperCam on board Mars 2020, ISEM, Ma_Miss and MicrOmega on board ExoMars 2020.

\section{$1 \quad$ Introduction}

Searching for molecular biosignatures is one of the primary goals of international Mars exploration programs (Des Marais et al., 2008; Walter et al., 2016).

Two upcoming robotic missions, NASA Mars 2020 (Williford et al., 2018) and ESA ExoMars 2020 (Vago et al., 2017), will employ space flight instruments based on Near InfraRed (NIR) vibrational spectroscopy to inspect the presence of organic matter at the respective landing sites. Specifically, Mars 2020 will be equipped with a remote-sensing instrument located on the "head" of the rover's mast, SuperCam, which is a combined remote-sensing instrument implementing several techniques (Wiens et al., 2017): Laser Induced Breakdown Spectroscopy (LIBS) (1064 nm laser), to measure elemental composition of targets up to $7 \mathrm{~m}$ distance from the rover; Raman (532 $\mathrm{nm}$ laser), TimeResolved Fluorescence (TRF), visible and Near InfraRed (NIR) reflectance spectroscopy (in the spectral ranges 400-900 $\mathrm{nm}$ and 1.3-2.6 $\mu \mathrm{m}$, respectively), to investigate mineralogy and presence of possible organics.

ExoMars 2020 will have 3 NIR instruments, namely ISEM (Infrared Spectrometer for ExoMars), Ma_MISS (Mars Multispectral Imager for Subsurface Studies), and MicrOmega (Vago et al., 2017). ISEM is a spectrometer mounted on the "head" of the rover's mast, co-aligned with the panoramic camera PanCam, which will measure IR spectra of solar light reflected by surficial targets in the spectral range from 1.15 to $3.3 \mu \mathrm{m}$, to determine mineralogical composition at hundreds of meters distance, with a spatial resolution of 3-10 cm (Korablev et al., 2017). Together with PanCam, ISEM will be tasked to select remotely the target site to be analysed more closely with other payload instruments. Ma_MISS is a miniaturized spectrometer integrated with the rover's drill, capable of reaching $2 \mathrm{~m}$ depth, which will acquire reflectance spectra in the spectral range from 0.5 to $2.3 \mu \mathrm{m}$, with a spatial resolution of $120 \mu \mathrm{m}$, and study stratigraphy and mineralogical composition as a function of depth (De Sanctis et al., 2017). The capability to reach the subsurface will facilitate investigation of environments with higher preservation potential, and Ma_MISS in situ measurements will provide information on subsurface materials in their natural setting before crushing and subsequent analysis with MicrOmega. MicrOmega is a visible and NIR imaging microspectrometer, capable of acquiring monochromatic images at high resolution $(20 \mu \mathrm{m} \times 20 \mu \mathrm{m}$ per pixel $)$ on a $5 \mathrm{~mm} \times 5 \mathrm{~mm}$ field of view, with $20 \mathrm{~cm}^{-1}$ spectral sampling from 0.95 to $3.65 \mu \mathrm{m}$, along with few images at discrete wavelengths from 0.5 to $0.9 \mu \mathrm{m}$ (Bibring et al., 2017). This instrument will characterize mineralogical composition and presence of organics at a scale of mineral grains, identifying non-destructively regions of interest for further examination with other payload instruments. 
Given the importance of spectroscopic analysis to select the most interesting samples to further study with other payload instruments, a correct interpretation of vibrational spectroscopic data is essential for the success of these missions. However, the great variety of environmental factors and physicochemical interactions that occur between organic molecules and minerals make vibrational spectra quite complex (Fornaro et al., 2013b). Vibrational spectroscopy is particularly sensitive to moleculemineral interactions because different chemical functional groups give rise to characteristic vibrational bands that undergo significant changes as consequence of such interactions. Indeed, shifts of vibrational frequencies of molecular functional groups and mineral surface sites involved in the interaction can be observed to higher values in case the chemical bonds of these functional groups are strengthened, or to lower values in case they are weakened by the interaction. Band intensity variations can occur depending on molecular spatial arrangements as imposed by surface selection rules. New bands appear in the spectra due to formation of chemical bonds as a consequence of chemisorption. As an example, in the case of important biomarkers such as the components of nucleic acids, remarkable changes can be observed in the following cases: (i) the phosphate group forms covalent bonds with surface sites that lower symmetry and a splitting of its symmetric stretching mode is observed (Fornaro et al., 2018a); (ii) the carbonyl or amino groups of the nucleobases are involved in hydrogen bonds that weaken their chemical bonds and their stretching vibrational modes undergo red-shifts up to hundreds of $\mathrm{cm}^{-1}$ (Fornaro et al., 2016; Fornaro et al., 2015a; Fornaro et al., 2015b); and (iii) nucleobases are adsorbed parallel to the surface, cancelling the dynamic dipole moment perpendicular to the surface for vibrational modes in the plane of the aromatic ring, and no bands in the spectrum will be observed for these modes (Fornaro et al., 2013b). The nature of physico-chemical interactions established between molecules and minerals are affected by multiple factors: molecular properties; mineral characteristics; molecule-mineral concentration ratio; and environmental conditions of temperature, pressure, ionic strength, pH, presence of reactive species etc. (Fornaro et al., 2013a; Fornaro et al., 2018 b). For instance, at very high molecular concentrations, nucleotides and related molecules tend to form clusters on the mineral surface through strong intermolecular interactions of stacking or hydrogen bonds among nucleobases, with spectroscopic characteristics similar to those of the molecular solid. Therefore, in these cases, it is not possible to observe the spectroscopic features due to moleculemineral interactions. Moreover, $\mathrm{pH}$ influences the molecular protonation state and surface charge and, hence, the possible involvement of electrostatic interactions in the adsorption process. Furthermore, some ions can inhibit bonding to surface sites by interacting with specific molecular functional groups, or favor molecular adsorption by acting as bridges with the mineral surface sites and forming surface complexes with the molecules.

Organic molecules and minerals on Mars are also affected by chemical weathering due to irradiation and oxidative degradation (Fornaro et al., 2018c and references therein; Pavlov et al., 2002). Indeed, the present atmosphere of the planet enables mid- and near-UV radiation, galactic cosmic rays (GCR) and solar energetic protons (SEP) to reach the surface. The RAD instrument on board the Curiosity rover has measured a flux of ionizing radiations from GCR of $233 \pm 12 \mu$ Gray per day, which has a negligible effect on survivability of possible microbial lifeforms on Mars, with sporadic events of SEP that last a few days and increase the dose of about $50 \mu$ Gray (Hassler et al., 2014). Moreover, even though GCR can penetrate several meters in the Marian soil, measurable effects on organic matter apparently require hundreds of millions of years (Gerakines et al., 2012). On the other hand, organic molecules effectively absorb UV radiation, causing electronic excitation and photochemical reactions at very short timescales of a few hours (Fornaro et al., 2013b; Fornaro et al., 2018a; ten Kate, 2010). In addition, even though UV penetrates only a few $\mu \mathrm{m}$ or $\mathrm{mm}$ into the soil, aeolian erosion constantly exposes fresh material to radiation. As a consequence, it is crucial to investigate the effects of UV radiation on organic molecules embedded in mineral matrices mimicking the martian soil, in order to validate hypotheses about the nature of the organic compounds detected so far at the surface of Mars 
by the Curiosity rover (Eigenbrode et al., 2018; Freissinet et al., 2015; Glavin et al., 2013; Steele et al., 2018, 2012), as well as organics that will be possibly found by the next rover missions Mars 2020 collecting surficial samples or ExoMars 2020 collecting subsurface samples. The ExoMars 2020 landing site, Oxia Planum, underwent an extensive aeolian erosion that exposed at the surface material of less than 100 million years (Vago et al., 2017). As estimated by previous studies (Fornaro et al., 2018c), we would expect that GCR and SEP had a limited effect on possible organics in this site, while UV degradation occurred at much shorter timescales but only in the near surface. However, UV also causes secondary effects such as photo-induced formation of oxidants in the soil (Lasne et al., 2016), which might cause oxidative degradation up to a depth in the martian soil that is difficult to predict. Specifically, perchlorates have been detected both by orbital observations and in situ analyses by the Phoenix lander and the Curiosity rover, at a concentration between 0.05 and $1.05 \mathrm{wt} \%$ (Clark and Kounaves, 2016). Perchlorates have also been found in the martian meteorite EETA79001 (with a concentration of $0.6 \pm 0.1 \mathrm{ppm}$ by mass) (Kounaves et al., 2014), confirming their ubiquity on Mars. It is also true that ExoMars will analyse samples that have been in the subsurface for many millions of years at constant temperature of about $-60^{\circ} \mathrm{C}$, at which perchlorates are more stable and oxidation kinetics is very slow. Nevertheless, it is not possible to exclude that the interactions of perchlorates with GCR (capable of penetrating many meters) cause decomposition of perchlorate also at low temperature, giving rise to oxychlorine species, radicals, molecular oxygen and hydrogen peroxide, which in turn may degrade organics. Hydrogen peroxide is characterized by low thermal stability and can produce hydroxyl and peroxide radicals in the presence of ferrous minerals through the Fenton process (Foustoukos and Stern, 2012). Such chemical weathering phenomena might cause profound alterations of the original material, such as breakage of chemical bonds and formation of new molecular species, significantly influencing relative spectroscopic features. Such transformations must be taken into account to redefine molecular targets for life detection.

For these reasons, assignment of spectroscopic features cannot be based solely on databases for pure minerals and pure molecules measured under terrestrial ambient conditions; rather, it is indispensable to perform laboratory studies with analogs of the martian soil, prepared simulating realistically the martian environment, to interpret accurately mission data. In addition, NIR data and relative vibrational mode assignments for organics, both pure and adsorbed on mineral matrices, are scarce in the literature (Clark et al., 2009). Indeed, the only fundamental vibrational modes in this spectral region for organics are $\mathrm{O}-\mathrm{H}, \mathrm{N}-\mathrm{H}$ and C-H stretching, and they occur around $3000 \mathrm{~cm}^{-1}$ where water gives strong and broad absorption, potentially obscuring molecular features. Beyond these fundamental bands, organics present overtones and combination bands in the NIR, but these modes are forbidden by primary vibrational selection rules, so they are usually very weak and often covered by much more intense mineral bands. As consequence, most literature studies for organics focus on the mid-IR spectral range, where very intense fundamental bands and the fingerprint region for organic molecules are present. Therefore, there is a great need of complementing vibrational studies for organics in the NIR, in order to be able to detect and identify organics on Mars from data acquired in this spectral range.

In this paper, we present laboratory analog studies concerning: (i) preparation of analog samples, obtained adsorbing relevant organic molecules - i.e. a plausible precursor of the chlorohydrocarbons detected on Mars by Curiosity, namely phthalic acid, as well as the biomarkers of extant life Lphenylalanine and L-glutamic acid, which are proteomic amino acids, and adenosine 5'monophosphate, which is a nucleic acid component - at various concentrations on a common martian clay mineral, montmorillonite, doped with $1 \mathrm{wt} \%$ of magnesium perchlorate; (ii) mid-UV irradiation processing, to investigate possible transformations of organics and define more accurately targets to search in surficial samples; (iii) Near InfraRed characterization in situ, aided by computational spectroscopy at Density Functional Theory level to facilitate assignment of vibrational modes. 
These investigations represent the starting point of a systematic study with analog samples composed of several combinations of relevant minerals, salts, oxidants, and different classes of organic compounds at various concentrations, prepared with methods mimicking natural processes that possibly occurred through time at the landing sites selected for ExoMars 2020 and Mars 2020, i.e. Oxia Planum and Jezero Crater, respectively. These studies will allow the assembly of custom databases of vibrational features to be used as a reference dataset to deconvolve complex features of actual martian samples and interpret in situ NIR measurements to assist ExoMars 2020 and Mars 2020 in identifying organics at the respective landing sites.

\section{$2 \quad$ Materials and Methods}

\subsection{Preparation and Characterization of Mars Soil Analog Samples}

As mineral substrate, we used a Ca-rich montmorillonite ("Cheto"), from County of Apache, State of Arizona, USA, called "Cheto" SAz-1, purchased from the Clay Mineral Society. Mineral phases were characterized at the Earth and Planets Laboratory of the Carnegie Institution for Science (Washington DC, USA) by making use of: (i) X-Ray Fluorescence (XRF) using a SPECTRO XEPOS (AMETEK) instrument to determine chemical composition; (ii) powder X-Ray Diffraction (XRD) using a Bruker D2 Phaser instrument to confirm mineralogy; and (iii) Isotope Ratio Mass Spectrometry (IRMS) using a Thermo Scientific Delta V Plus mass spectrometer interfaced with a CE Instruments NC 2500 series Elemental Analyser (EA) to estimate the organic content originally present in the montmorillonite sample. Then, we devised a cleaning procedure to extract the organic contamination from this mineral through four extraction steps with different solvent systems: 1) Methanol + sonication for $1 / 2 \mathrm{~h}$; 2) $40 \%$ Acetone in water + sonication for $1 / 2 \mathrm{~h} ; 3) 0.1 \mathrm{M}$ sodium pyrophosphate $\left(\mathrm{Na}_{4} \mathrm{P}_{2} \mathrm{O}_{7} \bullet 10 \mathrm{H}_{2} \mathrm{O}\right)+$ sonication for $1 / 2 \mathrm{~h}$; 4) Water + rotation for $1 / 2 \mathrm{~h}$. We used a mineral concentration of $150 \mathrm{~g} \mathrm{~L}^{-1}$ in each step, and we alternated each extraction step with centrifugation and supernatant separation. Eventually we ovendried the pellet at $50{ }^{\circ} \mathrm{C}$.

Given the ubiquity of perchlorates in the martian soil, we also prepared montmorillonite samples containing $1 \mathrm{wt} \%$ of magnesium perchlorate. Specifically, we impregnated the previously treated montmorillonite with $1 \mathrm{wt} \%$ of $\mathrm{Mg}\left(\mathrm{ClO}_{4}\right)_{2} \cdot 6 \mathrm{H}_{2} \mathrm{O}$ (Fisher Scientific) dissolved in milli-Q water. We agitated the suspension through magnetic stirring to homogenize and then we dried in an oven at 40 ${ }^{\circ} \mathrm{C}$.

To verify possible changes in mineral properties due to the presence of $1 \mathrm{wt} \%$ of magnesium perchlorate, we characterized the montmorillonite samples before and after impregnation with magnesium perchlorate through several techniques: XRD, IR, Raman, Transmission Electron Microscopy (TEM), Brunauer-Emmett-Teller (BET) surface area analysis, and solid state Nuclear Magnetic Resonance (NMR). IR measurements were performed using a single beam double pendulum interferometer Vertex 70v (Bruker), equipped with a Praying Mantis ${ }^{\mathrm{TM}}$ Diffuse Reflection Accessory (Harrick DRIFT), in order to measure diffuse reflectance spectra, available at INAF-Astrophysical Observatory of Arcetri (Florence, Italy). Raman spectra and images were collected using a Witec $\alpha$ Scanning Near-Field Optical Microscope that has been customized to incorporate confocal Raman spectroscopic imaging, available at the Earth and Planets Laboratory of the Carnegie Institution for Science (Washington DC, USA). The excitation source is a frequency-doubled solid-state YAG laser $(532 \mathrm{~nm})$ operating between 0.3 and $1 \mathrm{~mW}$ output power (dependent on objective), as measured at the sample using a laser power meter. Objective lenses used included a x100 LWD and a x20 LWD with 
a $50 \mu \mathrm{m}$ optical fiber acting as the confocal pin hole. Spectra were collected on a Peltier-cooled Andor EMCCD chip, after passing through a f $/ 4300 \mathrm{~mm}$ focal length imaging spectrometer typically using a 600 lines/mm grating. The lateral resolution of the instrument is as small as $360 \mathrm{~nm}$ in air when using the x100 LWD objective, with a focal plane depth of $\sim 800 \mathrm{~nm}$. A cosmic ray reduction routine was used to reduce the effects of stray radiation on Raman images, as was image thresholding to reject isolated bright pixels. Fluorescence effects were inhibited by the use of specific peak fitting and flattening. TEM measurements of the samples were performed using a JEOL100CX microscope, available at Sorbonne Universite (Paris, France). Specifically, samples in the form of bulk powders were suspended in ethanol and then deposited on 400-mesh copper grids covered with an ultrathin carbon membrane of 2-3 nm thickness. $\mathrm{N}_{2}$ adsorption-desorption isotherms at $-196{ }^{\circ} \mathrm{C}$ were obtained on a Micromeritics ASAP 2020 instrument, available at Sorbonne Université (Paris, France). Prior to measurement, the samples $(40 \mathrm{mg})$ were degassed under vacuum for 3 hours at $250{ }^{\circ} \mathrm{C}$. The BrunauerEmmett-Teller (BET) surface areas were calculated from the BET equation for a relative pressure $\left(\mathrm{P} / \mathrm{P}_{0}\right)$ range between 0.05 and $0.25 .{ }^{1} \mathrm{H}$ and ${ }^{27} \mathrm{Al}$ and ${ }^{29} \mathrm{Si}$ Magic angle spinning (MAS) nuclear magnetic resonance (NMR) spectra were obtained on a Bruker Advance III spectrometer equipped with a $2.5 \mathrm{~mm}$ and $4 \mathrm{~mm} \mathrm{H}-\mathrm{X}$ MAS probe, operating at frequency of $500.07 \mathrm{MHz}\left({ }^{1} \mathrm{H}\right), 99.36 \mathrm{MHz}$ $\left({ }^{29} \mathrm{Si}\right)$ and $130.30 \mathrm{MHZ}\left({ }^{27} \mathrm{Al}\right)$, available at Sorbonne Université (Paris, France). Chemical shifts were calibrated using the carboxyl signal of adamantane $(38.52 \mathrm{ppm})$ for ${ }^{1} \mathrm{H}$, TMS $(0 \mathrm{ppm})$ for ${ }^{29} \mathrm{Si}$ and $\mathrm{Al}\left(\mathrm{NO}_{3}\right)_{3}(0 \mathrm{ppm})$ for ${ }^{27} \mathrm{Al}$ as external standard. The ${ }^{1} \mathrm{H}$ experiment using $90^{\circ}$ pulse was recorded with a spinning rate of $14 \mathrm{kHz}$, with a number of scans of 128 and $1 \mathrm{~s}$ of recycle delay. Over an acquisition time of $40 \mathrm{~ms}$, the number of scans to obtain the spectra depends on the $\mathrm{S} / \mathrm{N}$ obtained for each sample. The ${ }^{27} \mathrm{Al}$ experiment using $30^{\circ}$ pulse was recorded in the same condition of spinning rate $(14 \mathrm{kHz})$, with 2048 scans, $263 \mathrm{kHz}$ spectral width, and $500 \mathrm{~ms}$ of recycle delay. The ${ }^{29} \mathrm{Si}$ experiment using $90^{\circ}$ pulse with a ${ }^{1} \mathrm{H}$ decoupling spinal was recorded in the same condition of spinning rate. The number of scans was 8192 and the recycling time D1 was $10 \mathrm{~s}$. The Spectra were processed with a zero-filling factor of 2 and without an exponential decay.

We used treated montmorillonite samples as substrates for performing adsorption experiments of adenosine 5'-monophosphate sodium salt (AMP), L-glutamic acid monosodium salt monohydrate $98 \%$ (GLU), L-phenylalanine $\geq 98 \%$ (PHE), and phthalic acid $\geq 99.5 \%$ (PHA) (all purchased from SigmaAldrich), both as individual molecules and as a mixture (MIX), at three different concentrations, i.e. 5 $\mathrm{wt} \%, 1 \mathrm{wt} \%$ and $0.1 \mathrm{wt} \%$. Chemical structures for these molecules are shown in Figure 1.

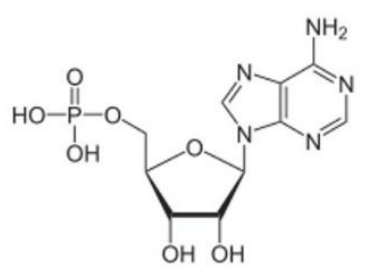

Adenosine 5'monophosphate (AMP)<smiles>N[C](CCC(=O)O)C(=O)O</smiles>

L-Glutamic acid (GLU)

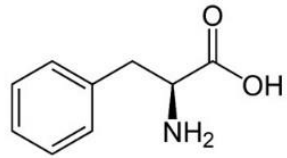

L-Phenylalanine (PHE)

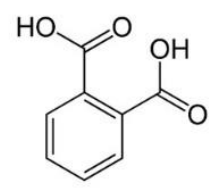

Phthalic acid (PHA)

Figure 1. Chemical structures for adenosine 5'-monophosphate (AMP), L-glutamic acid (GLU), Lphenylalanine (PHE), and phthalic acid (PHA). 
In order to simulate the formation of molecule-mineral complexes in diluted aqueous environments presumably present on early Mars, we performed equilibrium adsorption experiments in the aqueous phase (Fornaro et al., 2018a). Specifically, we dissolved specific amounts of the above-mentioned molecules, both individually and as a mixture, in a volume of milli-Q water much higher than the mineral porous volume, within molecular solubility, and then we mixed the mineral powder with such aqueous solutions using a mineral concentration of about $120 \mathrm{~g} \cdot \mathrm{L}^{-1}$. We vortexed such suspensions to favour homogeneous interaction between molecules and mineral, and then we put the suspensions on a test tube rotator for a time sufficient to reach the equilibrium state $(\approx 24 \mathrm{~h})$. After equilibrium adsorption, we dried in an oven at $40^{\circ} \mathrm{C}$ to simulate a desiccation process of liquid water bodies on early Mars. With this method, all molecules in the initial aqueous solution adsorb on the solid substrate. Specifically, we chose to prepare montmorillonite samples with three different molecular concentrations, i.e. $5 \mathrm{wt} \%, 1 \mathrm{wt} \%$ and $0.1 \mathrm{wt} \%$. This preparation method was advantageous because it is time-effective and it enables us to control the amount of molecules adsorbed on the solid substrate and the experimental conditions. In addition, these procedures maximize molecular interactions with mineral surfaces as well as molecular diffusion inside the mineral matrix; therefore, molecules establish physico-chemical interactions with mineral surfaces as in natural processes of adsorption.

\subsection{UV Irradiation Experiments and Near InfraRed Characterization}

We subjected the Mars soil analog samples at $5 \mathrm{wt} \%$ molecular concentration on montmorillonite containing $1 \mathrm{wt} \%$ of magnesium perchlorate to mid-UV irradiation processing. We chose the samples with the highest molecular concentration in order to observe the most obvious variations in the spectroscopic features due to UV irradiation, and with magnesium perchlorate to simulate realistically martian surficial samples. We used an experimental setup assembled at INAF-Astrophysical Observatory of Arcetri (Florence, Italy) that allows us to monitor the photochemistry in situ by Diffuse Reflectance Infrared Fourier Transform Spectroscopy (DRIFTS) analysis. Specifically, the UV light emitted by a Newport Xenon enhanced UV 300 W lamp with purified Xenon at 5-20 bar (wavelength range 185-2000 $\mathrm{nm}$ ) is focused directly on the sample through an optical fiber of $800 \mu \mathrm{m}$ spot size. With this setup, the irradiated spot of the sample presents an area of $7.07 \mathrm{~mm}^{2}$ and the UV flux focused on the sample is $2.75 \times 10^{17}$ photons $\mathrm{s}^{-1} \mathrm{~cm}^{-2}$ in the $200-400 \mathrm{~nm}$ spectral range, as measured through a single monochromator Spectro 320 scanning spectrometer (Instrument System). The optical fiber is inserted into the sample chamber of a single beam double pendulum interferometer VERTEX 70v (Bruker), equipped with a Praying Mantis ${ }^{\mathrm{TM}}$ Diffuse Reflection Accessory (Harrick DRIFT), in order to measure diffuse reflectance spectra of the sample in situ at regular intervals during UV irradiation (Figure 2). 


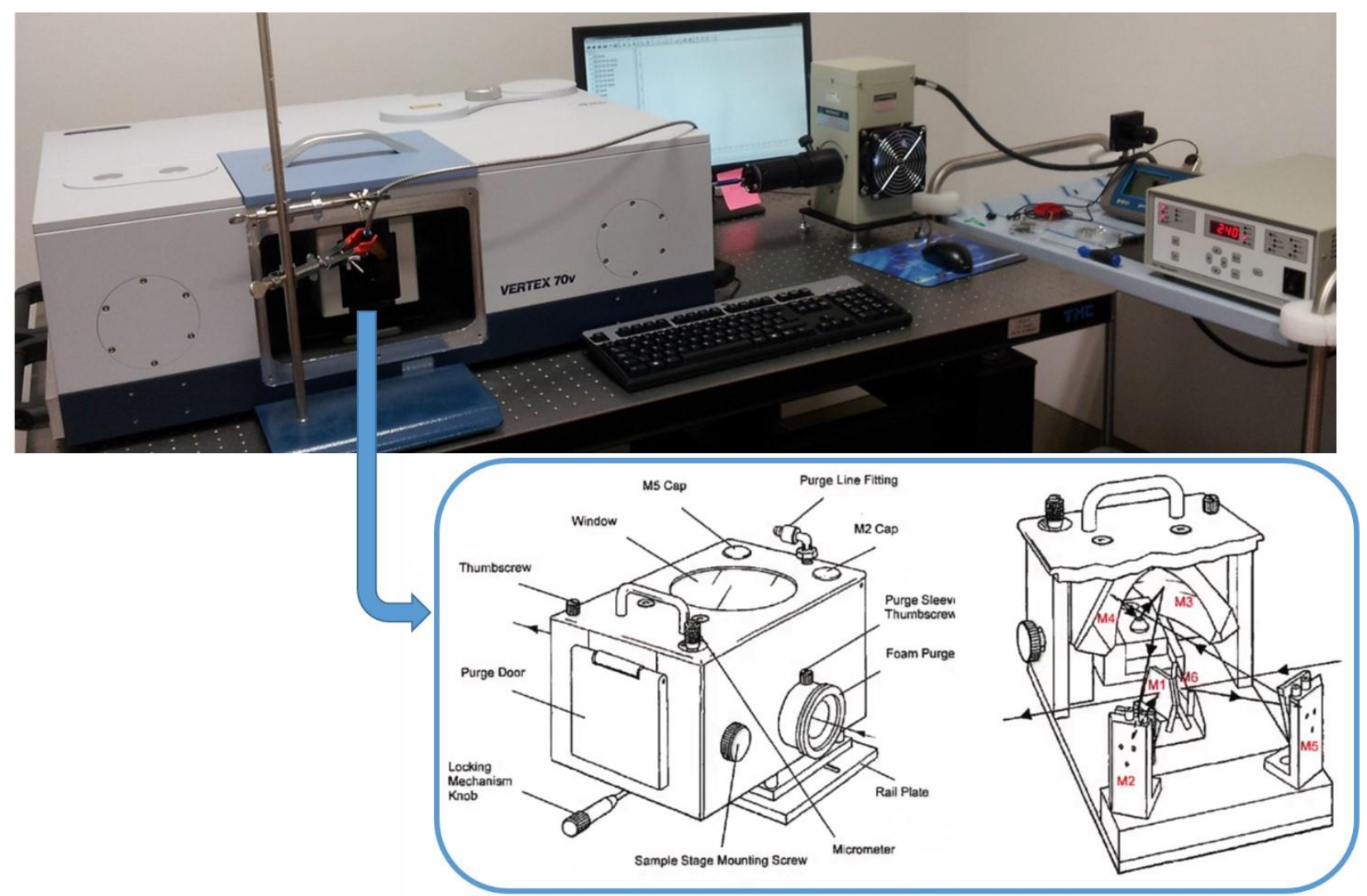

Figure 2. Experimental setup used for in situ UV irradiation experiments, with scheme of the Praying Mantis $^{\mathrm{TM}}$ Diffuse Reflection Accessory.

For these experiments, we acquired reflectance spectra pre-irradiation and during UV irradiation in the spectral range $400-8000 \mathrm{~cm}^{-1}$, using a resolution of $4 \mathrm{~cm}^{-1}, 100$ scan, Globar source, KBr beamsplitter, and a DTGS detector, but we focused our analysis only on the Near InfraRed (NIR) spectral region above $2000 \mathrm{~cm}^{-1}$, which is relevant to space flight instruments such as SuperCam (spectral range 1.3$2.6 \mu \mathrm{m}+0.4-0.85 \mu \mathrm{m}$ ) on board Mars 2020, Ma_MISS (spectral range 0.5-2.3 $\mu \mathrm{m}$ ), ISEM (spectral range 1.1-3.3 $\mu \mathrm{m}$ ) and MicrOmega (spectral range 0.95-3.65 $\mu \mathrm{m}+0.5-0.9 \mu \mathrm{m}$ ) on board ExoMars 2020. Furthermore, we acquired reflectance spectra also in the $8000-20000 \mathrm{~cm}^{-1}$ spectral region, using a Tungsten source, $\mathrm{CaF} 2$ beamsplitter and InGaAs detector.

We irradiated for a total time of 70 minutes under a flux of nitrogen at room temperature. Such short irradiation experiments at room temperature simulate the most intense martian irradiation that occurs in the equatorial region around noon.

We evaluated the percentages of degradation after 70 min of UV irradiation as:

$$
\% \text { degr }=\frac{\left[\left(A_{\text {pre }}-A_{\text {post }}\right) \times 100\right]}{A_{\text {pre }}}
$$

where $A_{\text {pre }}$ is the area of the molecular peak pre-irradiation and $A_{\text {post }}$ is the area of the same molecular peak post-irradiation. 


\subsection{Anharmonic Computational Spectroscopy Calculations}

To assign vibrational features in the NIR, it is necessary to carry out calculations at the anharmonic level that predict frequencies and intensities of overtones and combination bands. The anharmonic vibrational frequencies and IR intensities were obtained via a generalized second-order vibrational perturbation theory approach (GVPT2) (Barone, 2005; Barone et al., 2014; Bloino, 2015; Bloino et al., 2015), following the procedures recommended in Refs. (Bloino et al., 2016). According to the experimental conditions, the geometry optimizations started from conformers present in the solid state. All computations have been performed by means of density functional theory employing the B3LYP functional (Becke, 1993) with the double-zeta basis sets SNSD (Barone et al., 2014), and including Grimme's dispersion correction D3 (in conjunction with Becke-Johnson damping) (Ehrlich et al., 2011; Grimme et al., 2011, 2010). This approach has been well tested for structural and spectroscopy properties of biological molecules of astrochemical interest (Barone et al., 2015; Biczysko et al., 2018; Fornaro et al., 2014; Fornaro et al., 2015a; Fornaro et al., 2015b).

In GVPT2 computations, the default criteria for anharmonic resonances have been exploited, and variational corrections have been applied to both energies and IR intensities. Moreover, considering that the large amplitude-motion (LAM) vibrations, which cannot be well-described by perturbative approaches, may contaminate the overall VPT2 treatment and higher frequency vibrations, LAM-free VPT2 scheme have been used in this work (where all LAMs anharmonic constants are excluded from the VPT2) (Biczysko et al., 2018). For all molecules, vibrations with harmonic frequencies below 200 $\mathrm{cm}^{-1}$ have been considered as LAMs.

All calculations were performed with Gaussian 16 suite of computer codes (Frisch et al., 2016). VMSDraw (Licari et al., 2015) was used to visualize the normal modes and analyze in detail the outcome of vibrational computations and IR spectra.

\section{Results}

\subsection{Mineral Characterization}

XRF measurements showed the following chemical composition (\%): $\mathrm{SiO}_{2}=69.1, \mathrm{Al}_{2} \mathrm{O}_{3}=18.1, \mathrm{TiO}_{2}$ $=0.22, \mathrm{Fe}_{2} \mathrm{O}_{3}=1.75, \mathrm{MnO}=0.090, \mathrm{MgO}=6.49, \mathrm{CaO}=3.71, \mathrm{Na}_{2} \mathrm{O}=0.19, \mathrm{~K}_{2} \mathrm{O}=0.26, \mathrm{P}_{2} \mathrm{O}_{5}=0.01$, $\mathrm{SO}_{3}=0.059, \mathrm{~K}_{2} \mathrm{O}=0.26$.

We did not purify such montmorillonite sample from other mineral phases, so 1-2 wt\% of quartz was also present, as confirmed by the presence of a peak at $26.6^{\circ}$ in the XRD pattern shown in Supplementary Figure 1 of Supplementary Material.

The carbon content originally present in the montmorillonite sample, measured through IRMS-EA, was $0.11 \mathrm{wt} \%$. After the cleaning treatment, the carbon content was below the IRMS detection limit for Montmorillonite SAz-1.

XRD measurements showed that the treatment with sodium pyrophosphate caused cation exchange of doubly-hydrated $\mathrm{Ca}^{2+}$ with singularly-hydrated $\mathrm{Na}^{+}$, reducing montmorillonite interlayer distance of the basal plane (001) from $14.63 \AA$ to $12.54 \AA$ (Supplementary Figure 2). Based on a cation exchange capacity (CEC) of 120 meq/100g for montmorillonite and the amount of $\mathrm{Na}_{4} \mathrm{P}_{2} \mathrm{O}_{7} \bullet 10 \mathrm{H}_{2} \mathrm{O}$ used for extraction, we estimated the presence in the interlayers of about $60 \% \mathrm{Na}^{+}$and $40 \% \mathrm{Ca}^{2+}$. We also 
observed appearance of new peaks at 5.04, 5.45 and $8.56 \AA$ in the XRD pattern of treated montmorillonite, likely due to salts precipitated as consequence of the cleaning treatment.

As shown in Supplementary Figure 3, XRD patterns of montmorillonite (MONT) and montmorillonite doped with $1 \mathrm{wt} \%$ magnesium perchlorate (MONTP) present almost the same interlayer distance, intensity and band width. We only observed slight expansion of the interlayer distance of the (001) planes from $12.54 \AA$ for MONT to $12.63 \AA$ for MONTP $(\Delta \mathrm{d}(001)=0.09 \AA)$, that cannot be explained with intercalation of $\mathrm{Mg}^{2+}$, but it is likely due to hydration. We also observed disappearance of the peaks at $5.04,5.45$ and $8.56 \AA$, likely due to dissolution by perchlorate of the salts previously precipitated.

We did not observe any modifications of the mineral by IR or Raman characterization, as shown in Supplementary Figures 4 and 5.

TEM images of MONT and MONTP showed stacked layers with an interlayer spacing in agreement with XRD measurements (Supplementary Figure 6). Differences between samples before and after attack with perchlorate is not obvious since only $1 \mathrm{wt} \%$ of the latter was used. We suggest that $1 \mathrm{wt} \%$ of perchlorate does not strongly affect the montmorillonite layers. Statistics of layer spacings were done on several regions. The micrograph shown in Supplementary Figure 6 (on the right) exhibits some irregular layers compared to the ones before addition of perchlorate. A discontinuity in the layers can be underlined. These results should be carefully analysed since $1 \mathrm{wt} \%$ perchlorate cannot affect bulk properties of the sample.

However, BET analysis indicated that magnesium perchlorate affected montmorillonite surface area, which increased from $43 \mathrm{~m}^{2} / \mathrm{g}$ to $82 \mathrm{~m}^{2} / \mathrm{g}$. As can be seen on the adsorption-desorption isotherms in Supplementary Figure 7, the sample containing the $1 \mathrm{wt} \%$ of magnesium perchlorate presents more "textural porosity", probably due to alteration of surface charge that may cause disaggregation of the particles and an increase in the number of pores.

${ }^{27} \mathrm{Al}$ and ${ }^{29} \mathrm{Si}$ NMR spectra of samples before and after addition of magnesium perchlorate are superimposable without any difference, as shown in Supplementary Figure 8. The signal centered at 0 ppm in ${ }^{27} \mathrm{Al}$ MAS NMR is attributed to hexa-coordinated aluminium usually present in montmorillonite. The ${ }^{29} \mathrm{Si}$ signal centered around $-92 \mathrm{ppm}$ corresponds to Q3 species. For ${ }^{1} \mathrm{H}$ NMR, as shown in Supplementary Figure 9, a slight difference is observed in the form of the peaks, but overall the signals remain the same and the attribution is as follows: the signal around $4.4 \mathrm{ppm}$ is assigned to the protons of water, the one at 1.8 to the protons in $\mathrm{Si}-\mathrm{OH}$, and the one at 0.8 to the protons in $\mathrm{Mg}$ $\mathrm{OH}$. The negative ${ }^{1} \mathrm{H}$ NMR shifts at $-2.85 \mathrm{ppm}$ can be attributed to a strong shielding effect due to the presence of paramagnetic center in the sample.

\subsection{Near InfraRed Spectra Pre- and Post- UV Irradiation}

Figures 3, 4, 5, 6 and 7 report the NIR spectra pre-irradiation in the $2000-20000 \mathrm{~cm}^{-1}$ spectral region for AMP, GLU, PHE, PHA, and MIX adsorbed on montmorillonite at 5, 1 and $0.1 \mathrm{wt} \%$ concentration, along with frequency shifts with respect to the pure molecules in the solid state and tentative assignments based on DFT calculations at anharmonic level for the peaks in the most relevant 2740$8000 \mathrm{~cm}^{-1}$ spectral range. 


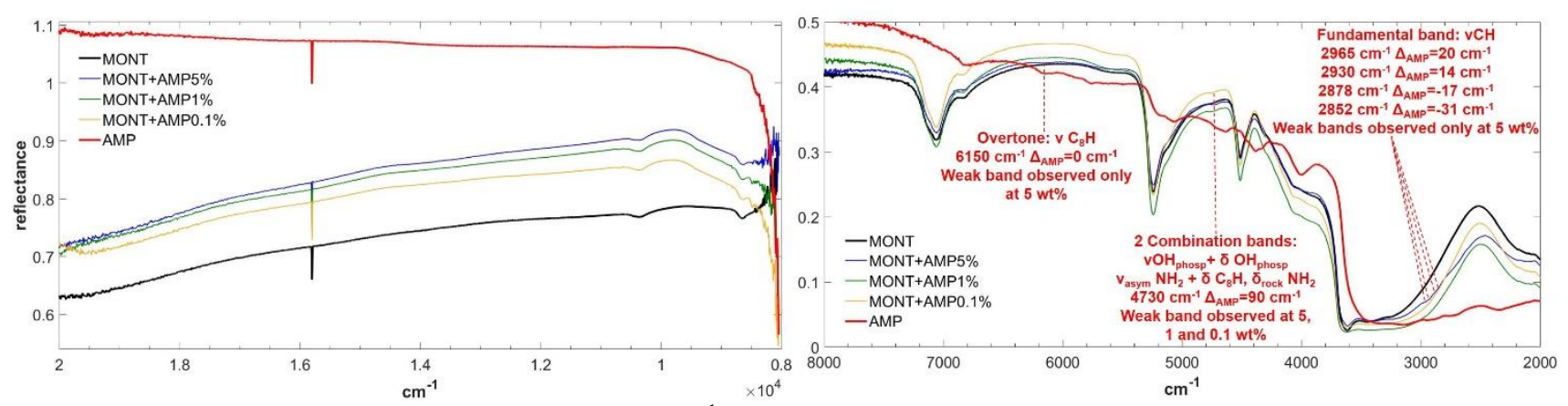

Figure 3. NIR spectra in the 2000-20000 $\mathrm{cm}^{-1}$ spectral range of AMP adsorbed on montmorillonite at 5,1 and $0.1 \mathrm{wt} \%$ concentration. Legend: $\Delta_{\mathrm{AMP}}=$ wavenumber shift with respect to the same peak of the pure molecule in the solid state; phosp = phosphate group; $v=$ stretching vibrational mode; $\delta=$ bending vibrational mode; rock= rocking in-plane vibrational mode; asym = asymmetric vibrational mode.
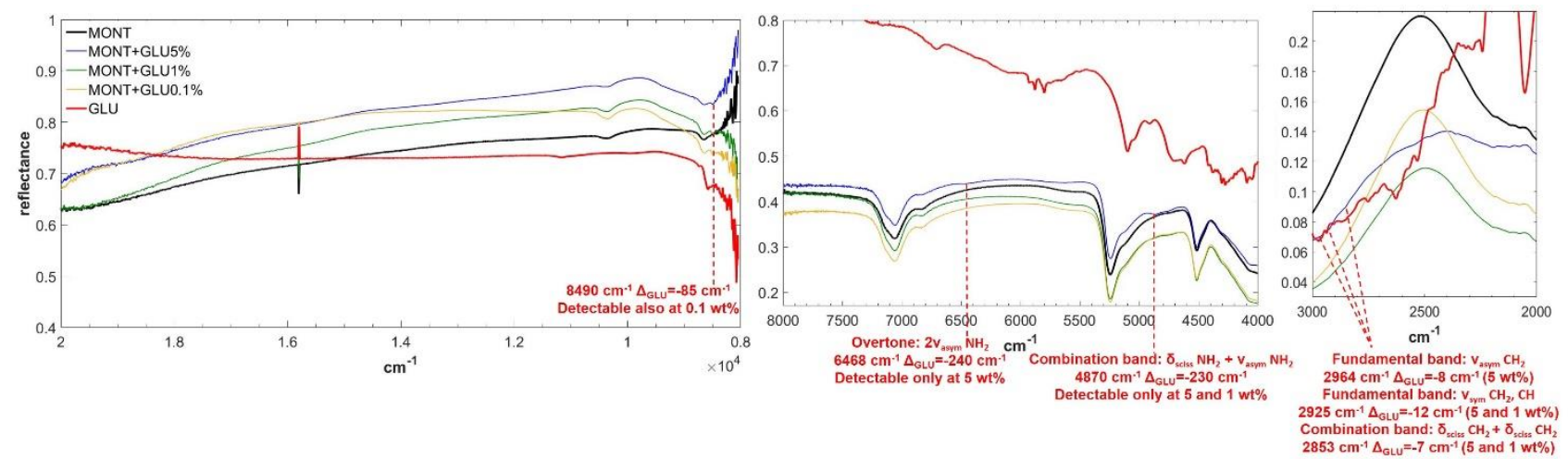

Figure 4. NIR spectra in the $2000-20000 \mathrm{~cm}^{-1}$ spectral range of GLU adsorbed on montmorillonite at 5,1 and $0.1 \mathrm{wt} \%$ concentration. Legend: $\Delta_{\mathrm{GLU}}=$ wavenumber shift with respect to the same peak of the pure molecule in the solid state; $v=$ stretching vibrational mode; $\delta=$ bending vibrational mode; sciss = scissoring in-plane vibrational mode; sym $=$ symmetric vibrational mode $;$ asym $=$ asymmetric vibrational mode.
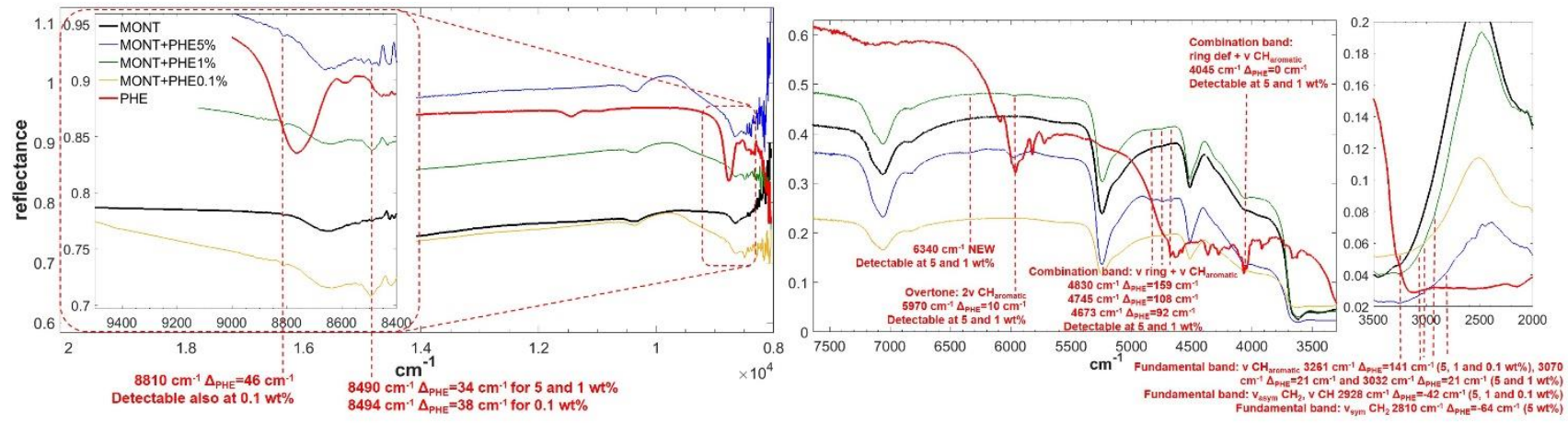

Figure 5. NIR spectra in the 2000-20000 $\mathrm{cm}^{-1}$ spectral range of PHE adsorbed on montmorillonite at 5,1 and $0.1 \mathrm{wt} \%$ concentration. Legend: $\Delta \mathrm{PHE}=$ wavenumber shift with respect to the same peak of the pure molecule in the solid state; $v=$ stretching vibrational mode; $\delta=$ bending vibrational mode; def 
= deformation vibrational mode; sym = symmetric vibrational mode; asym $=$ asymmetric vibrational mode.
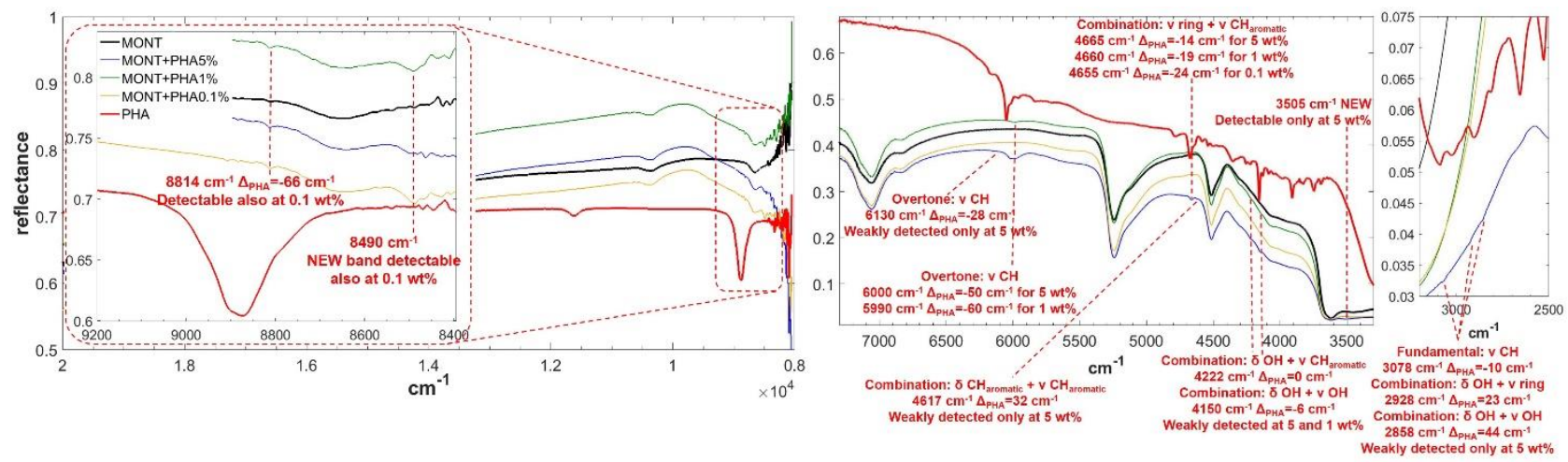

Figure 6. NIR spectra in the 2000-20000 $\mathrm{cm}^{-1}$ spectral range of PHA adsorbed on montmorillonite at 5,1 and $0.1 \mathrm{wt} \%$ concentration. Legend: $\Delta_{\mathrm{PHA}}=$ wavenumber shift with respect to the same peak of the pure molecule in the solid state; $v=$ stretching vibrational mode; $\delta=$ bending vibrational mode.
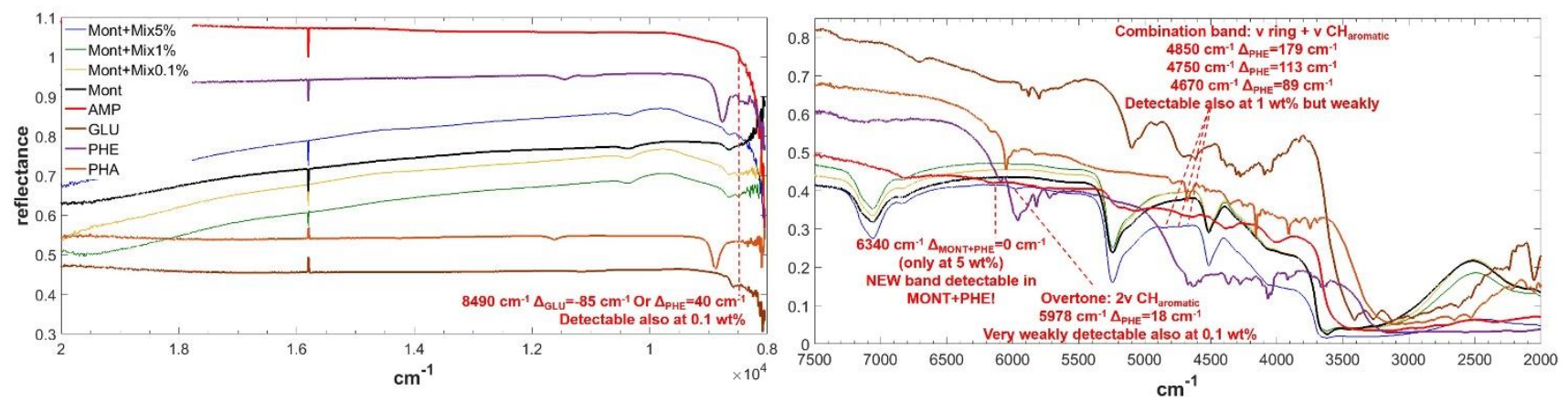

Figure 7. NIR spectra in the $2000-20000 \mathrm{~cm}^{-1}$ spectral range of MIX adsorbed on montmorillonite at 5,1 and $0.1 \mathrm{wt} \%$ concentration. Legend: $\Delta \mathrm{PHE}=$ wavenumber shift with respect to the same peak of the pure molecule in the solid state; $\Delta_{\mathrm{MONT}+\mathrm{PHE}}=$ wavenumber shift with respect to the same peak of PHE adsorbed on MONT; $v=$ stretching vibrational mode.

Table 1 reports the changes of molecular NIR features due to adsorption onto montmorillonite at different concentrations, presence of $1 \mathrm{wt} \%$ of magnesium perchlorate and $70 \mathrm{~min}$ of UV irradiation, along with the new features forming during UV irradiation. Tentative assignments are based on DFT calculations at anharmonic level, which are reported in detail in Supplementary Table 1.

Table 2 reports the changes of montmorillonite NIR features due to molecular adsorption at different concentrations, presence of $1 \mathrm{wt} \%$ of magnesium perchlorate and $70 \mathrm{~min}$ of UV irradiation. 
Table 1. Changes of molecular NIR features due to adsorption onto montmorillonite at different concentrations $(5,1$ and $0.1 \mathrm{wt} \%)$, presence of $1 \mathrm{wt} \%$ of magnesium perchlorate and $70 \mathrm{~min}$ of UV irradiation.

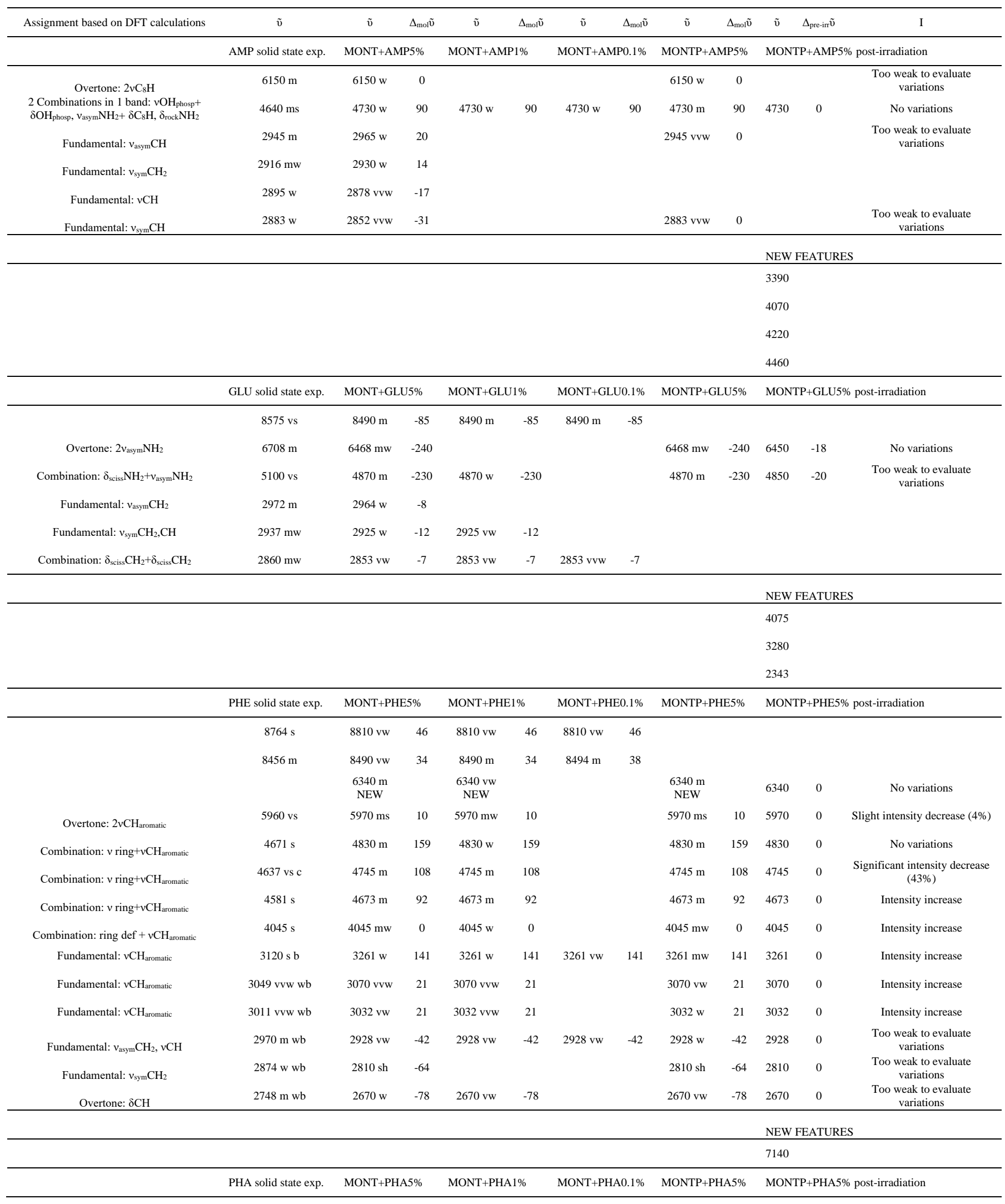




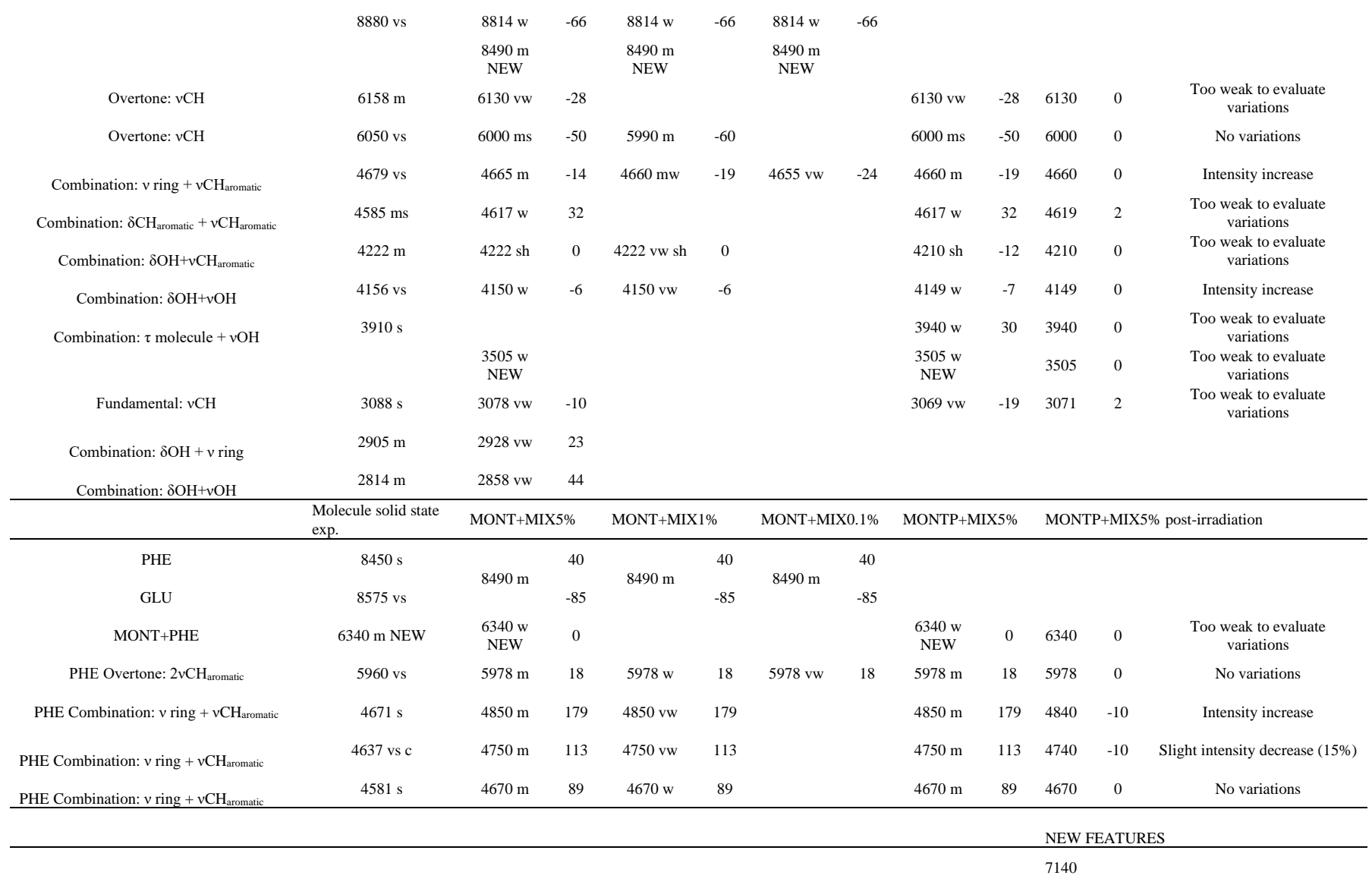

Legend: $\tilde{v}=$ wavenumber in $\mathrm{cm}^{-1} ; \Delta_{\text {mol }} \tilde{\mathrm{v}}=$ wavenumber shift $\left(\right.$ in $\left.\mathrm{cm}^{-1}\right)$ with respect to the same peak of the pure molecule in the solid state; $\Delta_{\text {pre-irr }} \tilde{=}=$ wavenumber shift $\left(\mathrm{in} \mathrm{cm}^{-1}\right)$ with respect to the same peak pre-irradiation; I = Intensity of the band; phosp = phosphate group; $v=$ stretching vibrational mode; $\delta=$ bending vibrational mode; $\tau=$ torsional vibrational mode; def $=$ deformation vibrational mode; sciss $=$ scissoring in-plane vibrational mode; rock= rocking in-plane vibrational mode; wagg = wagging out-of-plane vibrational mode; sym = symmetric vibrational mode; asym = asymmetric vibrational mode; $\mathrm{s}=$ strong band; $\mathrm{m}=$ medium band; $\mathrm{w}=$ weak band; $\mathrm{vw}=$ very weak band; $\mathrm{vvw}=$ extremely weak band; $\mathrm{c}=$ convolution of peaks; $\mathrm{b}=$ broad band; $\mathrm{wb}=$ within broad band.

Table 2. Changes of montmorillonite NIR features due to molecular adsorption at different concentrations $(5,1$ and $0.1 \mathrm{wt} \%)$, presence of $1 \mathrm{wt} \%$ of magnesium perchlorate and $70 \mathrm{~min}$ of UV irradiation.

\begin{tabular}{|c|c|c|c|c|c|c|c|c|c|c|c|c|c|c|}
\hline Assignment & $\tilde{\mathrm{v}}$ & $\tilde{\mathrm{v}}$ & $\Delta_{\text {MONT }} \tilde{v}$ & $\tilde{v}$ & $\Delta_{\text {MONT }} \tilde{v}$ & $\tilde{v}$ & $\Delta_{\text {MONT }} \tilde{v}$ & $\tilde{v}$ & $\Delta_{\text {MONT }} \tilde{v}$ & $\tilde{v}$ & $\Delta_{\text {MONTPŨ }}$ & $\tilde{v}$ & $\Delta_{\text {pre-irr }} \tilde{v}$ & I \\
\hline & MONT & MONT+AMP5\% & & \multicolumn{2}{|c|}{ MONT+AMP1\% } & \multicolumn{2}{|c|}{ MONT+AMP0.1\% } & \multicolumn{2}{|l|}{ MONTP } & \multicolumn{2}{|l|}{ MONTP+AMP5\% } & \multicolumn{3}{|c|}{$\begin{array}{l}\text { MONTP+AMP5\% post- } \\
\text { irradiation }\end{array}$} \\
\hline $\begin{array}{l}\text { Overtone: } \\
2 \mathrm{vAl}^{2} \mathrm{OH}^{\mathrm{a}}\end{array}$ & $7063 \mathrm{~s}$ & 7063 & 0 & 7063 & 0 & 7063 & 0 & 7063 & 0 & 7063 & 0 & 7048 & -15 & $\begin{array}{l}\text { Intensity } \\
\text { decrease } \\
(29 \%)\end{array}$ \\
\hline $\begin{array}{l}\text { Overtone: } \\
2 \mathrm{vH}_{2} \mathrm{O}^{\mathrm{b}}\end{array}$ & $6830 \mathrm{mw}$ & 6830 & 0 & 6830 & 0 & 6830 & 0 & 6830 & 0 & 6830 & 0 & 6830 & 0 & $\begin{array}{l}\text { Intensity } \\
\text { decrease up } \\
\text { to complete } \\
\text { disappearance } \\
(100 \%)\end{array}$ \\
\hline $\begin{array}{l}\text { Combination } \\
:(v+\delta) \mathrm{H}_{2} \mathrm{O}^{c}\end{array}$ & 5244 vs & 5244 & 0 & 5244 & 0 & 5244 & 0 & 5244 & 0 & 5244 & 0 & 5244 & 0 & $\begin{array}{l}\text { Significant } \\
\text { intensity } \\
\text { decrease } \\
(53 \%)\end{array}$ \\
\hline $\begin{array}{l}\text { Combination } \\
:(v+\delta) \mathrm{OH}^{\mathrm{b}}\end{array}$ & $4515 \mathrm{~s}$ & 4515 & 0 & 4515 & 0 & 4515 & 0 & 4515 & 0 & 4515 & 0 & 4515 & 0 & No variations \\
\hline \multirow[t]{2}{*}{$\begin{array}{l}\text { Fundamental } \\
: \mathrm{vOH}^{\mathrm{c}} \\
\end{array}$} & $3620 \mathrm{~s} \mathrm{wb}$ & 3620 & 0 & 3620 & 0 & 3620 & 0 & 3624 & 4 & 3620 & -4 & 3616 & -4 & $\begin{array}{l}\text { Intensity } \\
\text { increase }\end{array}$ \\
\hline & MONT & MONT+GLU5\% & & MONT & GLU1\% & MONT & GLU0.1\% & MONTP & & MONTP+GLU5\% & & \multicolumn{3}{|c|}{$\begin{array}{l}\text { MONTP+GLU5\% post- } \\
\text { irradiation }\end{array}$} \\
\hline
\end{tabular}




\begin{tabular}{|c|c|c|c|c|c|c|c|c|c|c|c|c|c|c|}
\hline $\begin{array}{l}\text { Overtone: } \\
2 v \mathrm{Al}_{2} \mathrm{OH}^{\mathrm{a}}\end{array}$ & $7063 \mathrm{~s}$ & 7063 & 0 & 7063 & 0 & 7063 & 0 & 7063 & 0 & 7063 & 0 & 7063 & 0 & $\begin{array}{l}\text { Intensity } \\
\text { decrease } \\
(28 \%)\end{array}$ \\
\hline $\begin{array}{l}\text { Overtone: } \\
2 \mathrm{vH}_{2} \mathrm{O}^{\mathrm{b}}\end{array}$ & $6830 \mathrm{mw}$ & 6830 & 0 & 6830 & 0 & 6830 & 0 & 6830 & 0 & 6830 & 0 & 6830 & 0 & $\begin{array}{l}\text { Intensity } \\
\text { decrease up } \\
\text { to nearly } \\
\text { complete } \\
\text { disappearance } \\
(86 \%)\end{array}$ \\
\hline $\begin{array}{l}\text { Combination } \\
:(v+\delta) \mathrm{H}_{2} \mathrm{O}^{c}\end{array}$ & 5244 vs & 5244 & 0 & 5244 & 0 & 5244 & 0 & 5244 & 0 & 5244 & 0 & 5244 & 0 & $\begin{array}{l}\text { Significant } \\
\text { intensity } \\
\text { decrease } \\
(56 \%)\end{array}$ \\
\hline $\begin{array}{l}\text { Combination } \\
:(v+\delta) \mathrm{OH}^{\mathrm{b}}\end{array}$ & $4515 \mathrm{~s}$ & 4515 & 0 & 4515 & 0 & 4515 & 0 & 4515 & 0 & 4515 & 0 & 4515 & 0 & No variations \\
\hline \multirow[t]{2}{*}{$\begin{array}{l}\text { Fundamental } \\
: \mathrm{vOH}^{\mathrm{c}}\end{array}$} & $3620 \mathrm{~s} \mathrm{wb}$ & 3620 & 0 & 3620 & 0 & 3620 & 0 & 3620 & 0 & 3620 & 0 & 3620 & 0 & $\begin{array}{l}\text { Intensity } \\
\text { increase }\end{array}$ \\
\hline & MONT & MONT+PHE5\% & & MONT & E1\% & MONT & $0.1 \%$ & MONTP & & MONTP+PHE5\% & & $\begin{array}{l}\text { MON1 } \\
\text { irradia }\end{array}$ & $\begin{array}{l}+\mathrm{PHF} \\
\mathrm{n}\end{array}$ & 7 post- \\
\hline $\begin{array}{l}\text { Overtone: } \\
2 v \mathrm{Al} 2 \mathrm{OH}^{\mathrm{a}}\end{array}$ & $7063 \mathrm{~s}$ & 7063 & 0 & 7063 & 0 & 7063 & 0 & 7063 & 0 & 7063 & 0 & 7053 & -10 & $\begin{array}{l}\text { Intensity } \\
\text { decrease } \\
(24 \%)\end{array}$ \\
\hline $\begin{array}{l}\text { Overtone: } \\
2 \mathrm{vH}_{2} \mathrm{O}^{\mathrm{b}}\end{array}$ & $6830 \mathrm{mw}$ & 6830 & 0 & 6830 & 0 & 6830 & 0 & 6830 & 0 & 6830 & 0 & 6830 & 0 & $\begin{array}{l}\text { Intensity } \\
\text { decrease up } \\
\text { to nearly } \\
\text { complete } \\
\text { disappearance } \\
(96 \%)\end{array}$ \\
\hline $\begin{array}{l}\text { Combination } \\
:(v+\delta) \mathrm{H}_{2} \mathrm{O}^{c}\end{array}$ & 5244 vs & 5244 & 0 & 5244 & 0 & 5244 & 0 & 5244 & 0 & 5244 & 0 & 5236 & -8 & $\begin{array}{l}\text { Significant } \\
\text { intensity } \\
\text { decrease } \\
(61 \%)\end{array}$ \\
\hline $\begin{array}{l}\text { Combination } \\
:(v+\delta) \mathrm{OH}^{\mathrm{b}}\end{array}$ & $4515 \mathrm{~s}$ & 4515 & 0 & 4515 & 0 & 4515 & 0 & 4515 & 0 & 4515 & 0 & 4515 & 0 & $\begin{array}{l}\text { Slight } \\
\text { intensity } \\
\text { decrease (6\%) }\end{array}$ \\
\hline \multirow[t]{2}{*}{$\begin{array}{l}\text { Fundamental } \\
: \mathrm{vOH}^{\mathrm{c}}\end{array}$} & $3620 \mathrm{~s} \mathrm{wb}$ & 3620 & 0 & 3620 & 0 & 3620 & 0 & 3620 & 0 & 3620 & 0 & 3620 & 0 & $\begin{array}{l}\text { Intensity } \\
\text { increase }\end{array}$ \\
\hline & MONT & MONT+PHA5\% & & MONT & $\mathrm{A} 1 \%$ & MONT & $0.1 \%$ & MONTP & & MONTP+PHA5\% & & $\begin{array}{l}\text { MON1 } \\
\text { irradia }\end{array}$ & $\begin{array}{l}+\mathrm{PH} / \\
\mathrm{n}\end{array}$ & $\%$ post- \\
\hline $\begin{array}{l}\text { Overtone: } \\
2 v \mathrm{Al} 2 \mathrm{OH}^{\mathrm{a}}\end{array}$ & $7063 \mathrm{~s}$ & 7063 & 0 & 7063 & 0 & 7063 & 0 & 7063 & 0 & 7063 & 0 & 7063 & 0 & $\begin{array}{l}\text { Intensity } \\
\text { decrease } \\
(25 \%)\end{array}$ \\
\hline $\begin{array}{l}\text { Overtone: } \\
2 \mathrm{vH}_{2} \mathrm{O}^{\mathrm{b}}\end{array}$ & $6830 \mathrm{mw}$ & 6830 & 0 & 6830 & 0 & 6830 & 0 & 6830 & 0 & 6830 & 0 & 6830 & 0 & $\begin{array}{l}\text { Significant } \\
\text { intensity } \\
\text { decrease } \\
(52 \%)\end{array}$ \\
\hline $\begin{array}{l}\text { Combination } \\
:(v+\delta) \mathrm{H}_{2} \mathrm{O}^{c}\end{array}$ & 5244 vs & 5244 & 0 & 5244 & 0 & 5244 & 0 & 5244 & 0 & 5244 & 0 & 5235 & -9 & $\begin{array}{l}\text { Significant } \\
\text { intensity } \\
\text { decrease } \\
(55 \%)\end{array}$ \\
\hline $\begin{array}{l}\text { Combination } \\
:(v+\delta) \mathrm{OH}^{\mathrm{b}}\end{array}$ & $4515 \mathrm{~s}$ & 4515 & 0 & 4515 & 0 & 4515 & 0 & 4515 & 0 & 4515 & 0 & 4515 & 0 & $\begin{array}{l}\text { Slight } \\
\text { intensity } \\
\text { decrease (8\%) }\end{array}$ \\
\hline \multirow[t]{2}{*}{$\begin{array}{l}\text { Fundamental } \\
: \mathrm{vOH}^{\mathrm{c}}\end{array}$} & $3620 \mathrm{~s} \mathrm{wb}$ & 3620 & 0 & 3620 & 0 & 3620 & 0 & 3620 & 0 & 3620 & 0 & 3620 & 0 & $\begin{array}{l}\text { Intensity } \\
\text { increase }\end{array}$ \\
\hline & MONT & MONT+MIX5\% & & MONT & $\mathrm{X} 1 \%$ & MONT & $0.1 \%$ & MONTP & & MONTP+MIX5\% & & $\begin{array}{l}\text { MON1 } \\
\text { irradia }\end{array}$ & & post- \\
\hline $\begin{array}{l}\text { Overtone: } \\
2 \mathrm{vAl}^{2} \mathrm{OH}^{\mathrm{a}}\end{array}$ & $7063 \mathrm{~s}$ & 7063 & 0 & 7063 & 0 & 7063 & 0 & 7063 & 0 & 7063 & 0 & 7063 & 0 & $\begin{array}{l}\text { Intensity } \\
\text { decrease } \\
(23 \%)\end{array}$ \\
\hline $\begin{array}{l}\text { Overtone: } \\
2 \mathrm{vH}_{2} \mathrm{O}^{\mathrm{b}}\end{array}$ & $6830 \mathrm{mw}$ & 6830 & 0 & 6830 & 0 & 6830 & 0 & 6830 & 0 & 6830 & 0 & 6830 & 0 & $\begin{array}{l}\text { Significant } \\
\text { intensity } \\
\text { decrease } \\
(61 \%)\end{array}$ \\
\hline $\begin{array}{l}\text { Combination } \\
:(v+\delta) \mathrm{H}_{2} \mathrm{O}^{c}\end{array}$ & 5244 vs & 5244 & 0 & 5244 & 0 & 5244 & 0 & 5244 & 0 & 5244 & 0 & 5240 & -4 & $\begin{array}{l}\text { Significant } \\
\text { intensity } \\
\text { decrease } \\
(47 \%)\end{array}$ \\
\hline $\begin{array}{l}\text { Combination } \\
:(v+\delta) \mathrm{OH}^{\mathrm{b}}\end{array}$ & $4515 \mathrm{~s}$ & 4515 & 0 & 4515 & 0 & 4515 & 0 & 4515 & 0 & 4515 & 0 & 4515 & 0 & No variations \\
\hline $\begin{array}{l}\text { Fundamental } \\
: \mathrm{vOH}^{\mathrm{c}}\end{array}$ & $3620 \mathrm{~s} \mathrm{wb}$ & 3620 & 0 & 3620 & 0 & 3620 & 0 & 3620 & 0 & 3620 & 0 & 3620 & 0 & $\begin{array}{l}\text { Intensity } \\
\text { increase }\end{array}$ \\
\hline
\end{tabular}

a (BISHOP et al., 2002); ${ }^{\text {b }}$ Madejová et al., 2006); ${ }^{\text {c }(M a d e j o v a ́, ~ 2003) . ~}$

Legend: $\tilde{v}=$ wavenumber in $\mathrm{cm}^{-1} ; \Delta_{\mathrm{MONT}} \tilde{v}=$ wavenumber shift $\left(\right.$ in $\left.\mathrm{cm}^{-1}\right)$ with respect to the same peak of MONT; $\Delta_{\text {pre-irr }} \tilde{v}=$ wavenumber shift $\left(\right.$ in $\left.\mathrm{cm}^{-1}\right)$ with respect to the same peak pre-irradiation; $\mathrm{I}=$ Intensity of the band; $v=$ stretching vibrational mode; $\delta=$ bending vibrational mode; $\mathrm{s}=$ strong band; $\mathrm{m}=$ medium band; $\mathrm{w}=$ weak band; $\mathrm{vw}=$ very weak band; $\mathrm{vvw}=$ extremely weak band; $\mathrm{b}=$ broad band; $\mathrm{wb}=$ within broad band.

Figures 8, 9, 10, 11 and 12 show the main changes in NIR features after 70 min of UV irradiation for the samples of $5 \mathrm{wt} \%$ molecular concentration on montmorillonite containing $1 \mathrm{wt} \% \mathrm{of} \mathrm{Mg}$ perchlorate. 


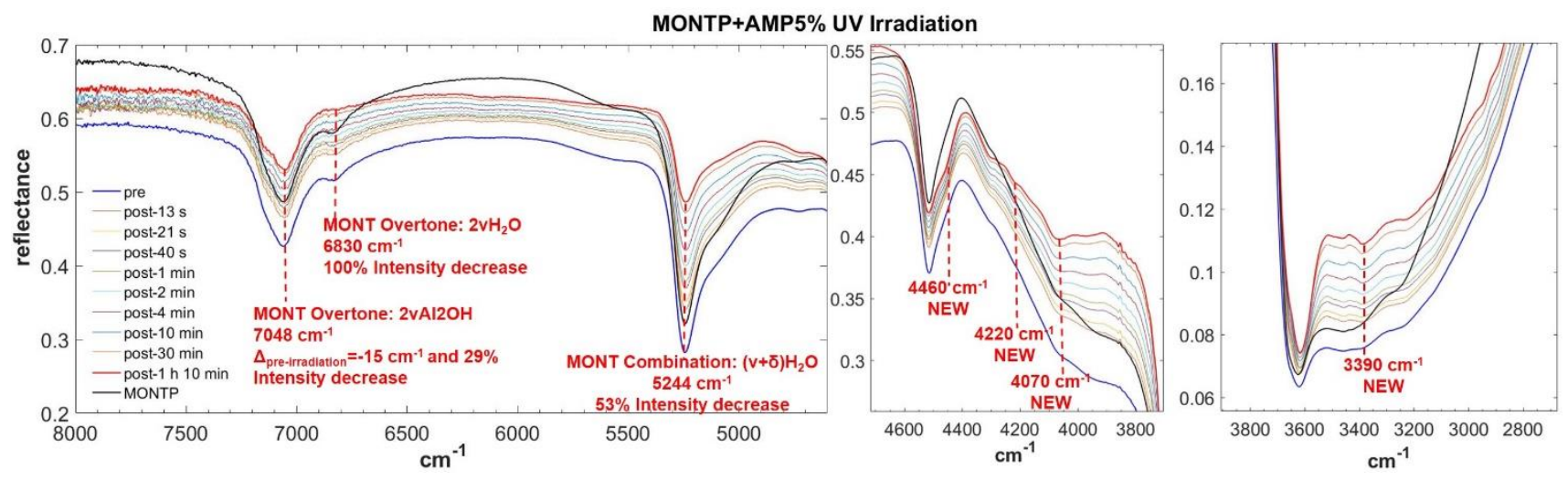

Figure 8. Main changes in NIR features after $70 \mathrm{~min}$ of UV irradiation for AMP 5 wt $\%$ on montmorillonite containing $1 \mathrm{wt} \%$ of $\mathrm{Mg}$-perchlorate. Legend: $\Delta_{\text {pre-irr }}=$ wavenumber shift with respect to the same peak pre-irradiation; $v=$ stretching vibrational mode; $\delta=$ bending vibrational mode.

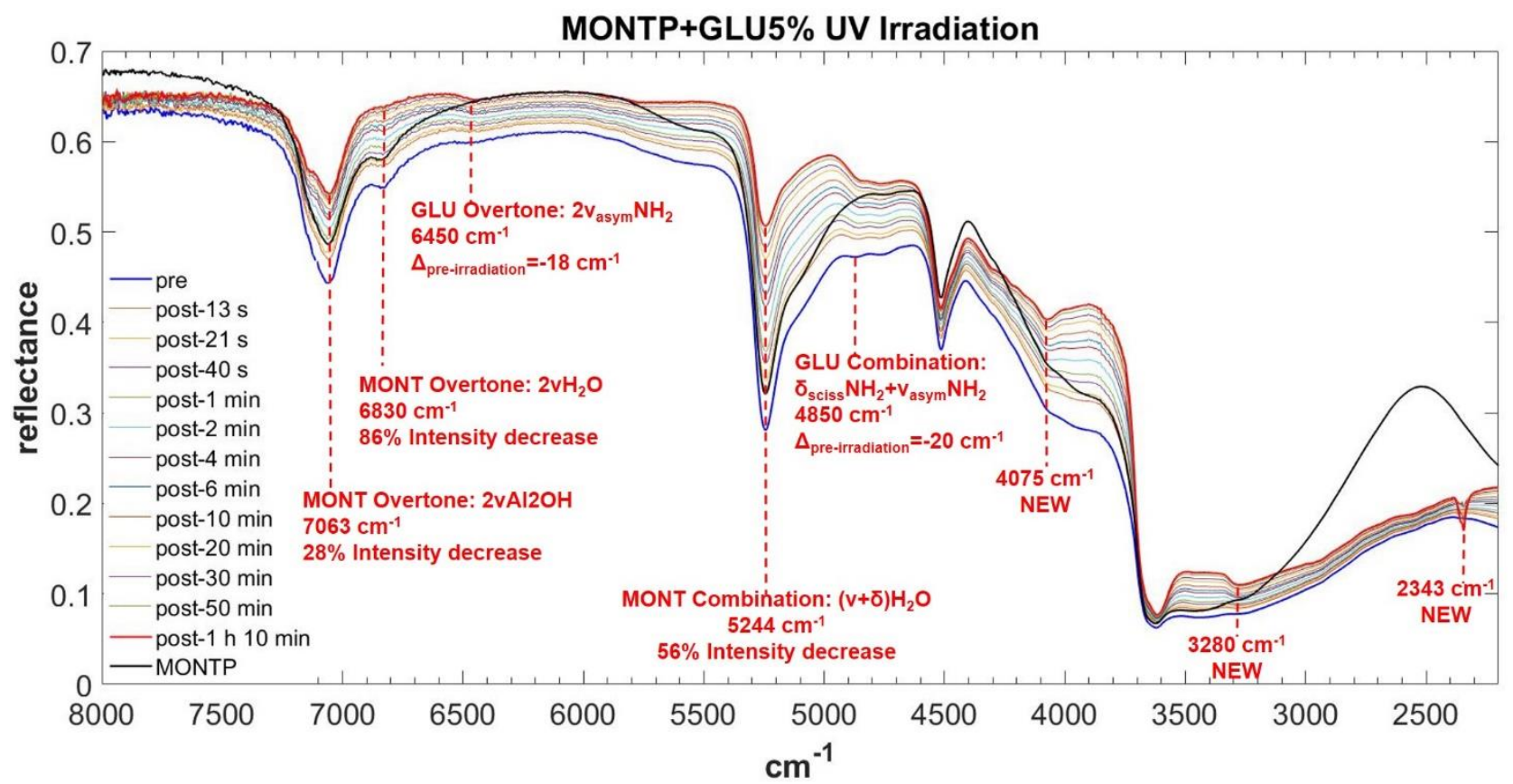

Figure 9. Main changes in NIR features after $70 \mathrm{~min}$ of UV irradiation for GLU 5 wt\% on montmorillonite containing $1 \mathrm{wt} \%$ of Mg-perchlorate. Legend: $\Delta_{\text {pre-irr }}=$ wavenumber shift with respect to the same peak pre-irradiation; $v=$ stretching vibrational mode; $\delta=$ bending vibrational mode; sciss $=$ scissoring in-plane vibrational mode; asym = asymmetric vibrational mode. 


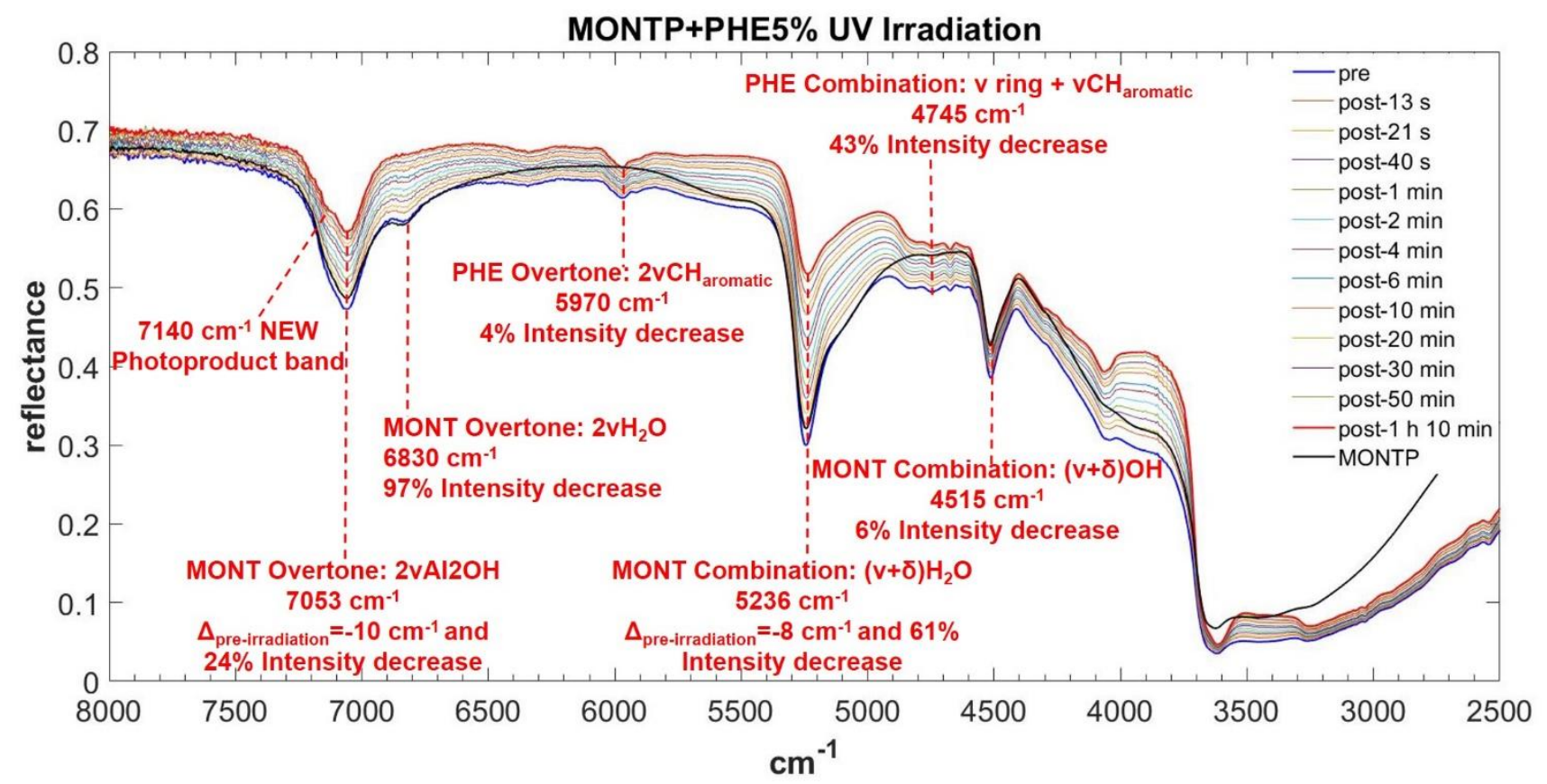

Figure 10. Main changes in NIR features after $70 \mathrm{~min}$ of UV irradiation for PHE $5 \mathrm{wt} \%$ on montmorillonite containing $1 \mathrm{wt} \%$ of Mg-perchlorate. Legend: $\Delta_{\text {pre-irr }}=$ wavenumber shift with respect to the same peak pre-irradiation; $v=$ stretching vibrational mode; $\delta=$ bending vibrational mode.

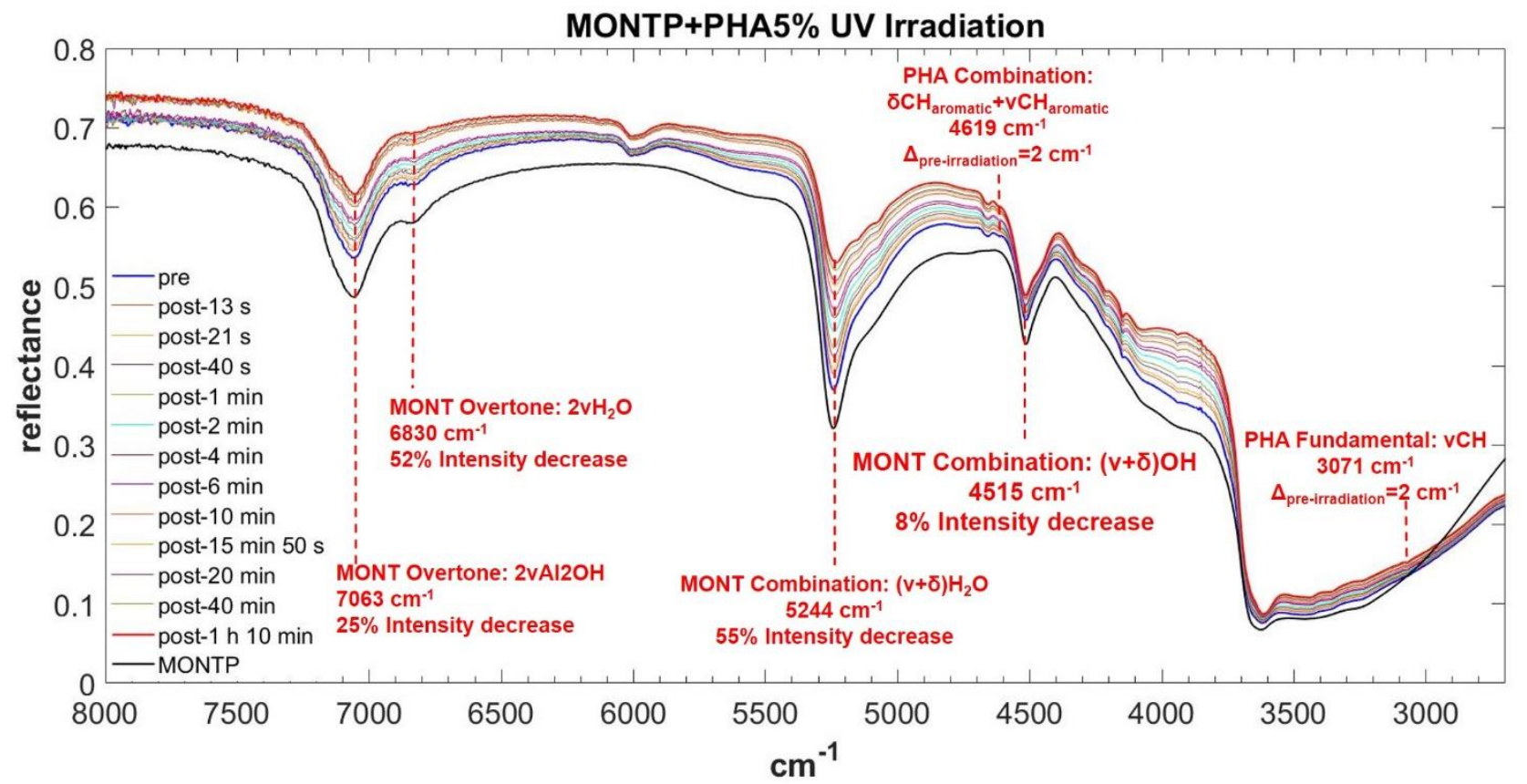

Figure 11. Main changes in NIR features after $70 \mathrm{~min}$ of UV irradiation for PHA $5 \mathrm{wt} \%$ on montmorillonite containing $1 \mathrm{wt} \%$ of Mg-perchlorate. Legend: $\Delta_{\text {pre-irr }}=$ wavenumber shift with respect to the same peak pre-irradiation; $v=$ stretching vibrational mode; $\delta=$ bending vibrational mode. 


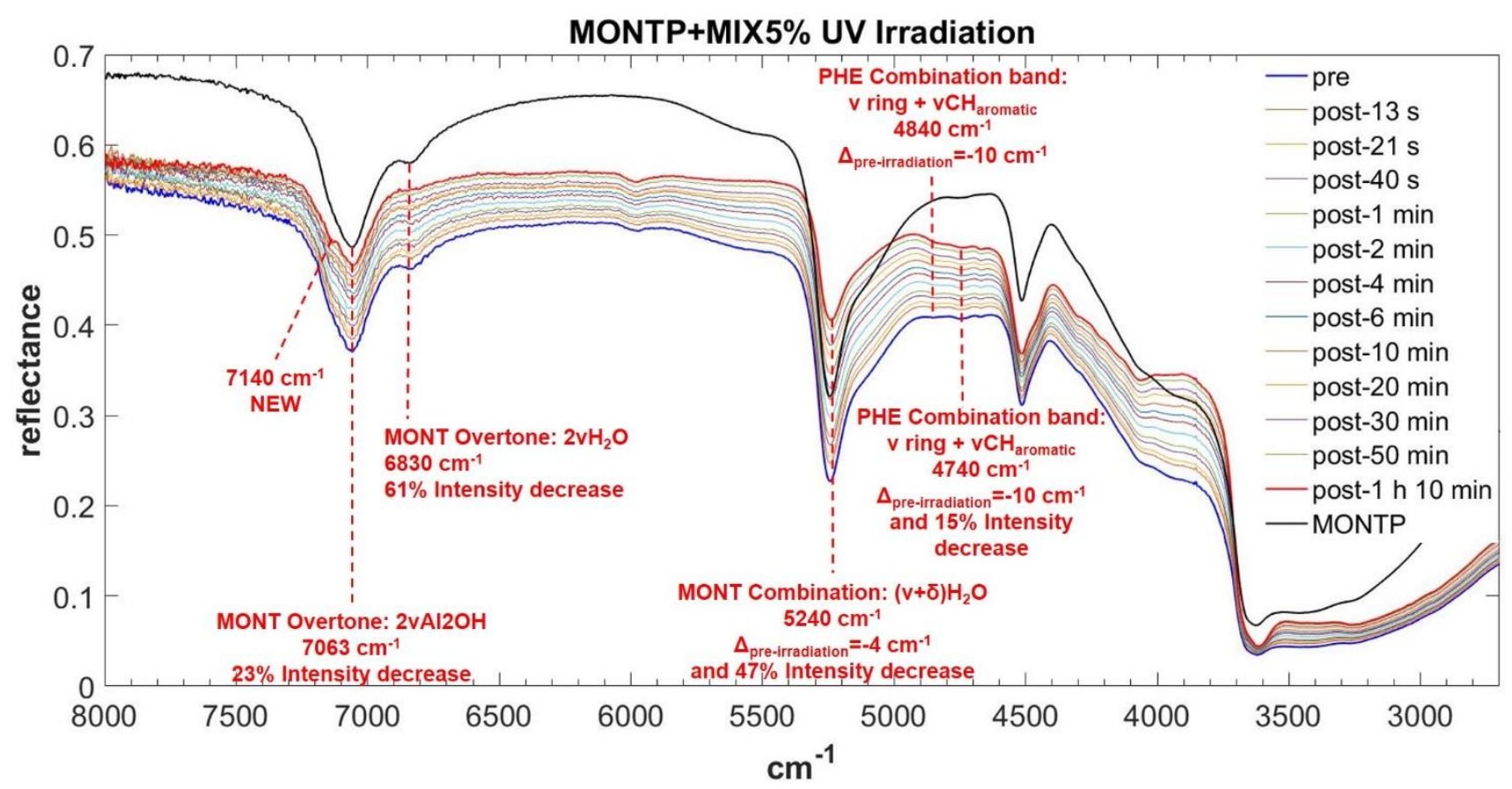

Figure 12. Main changes in NIR features after $70 \mathrm{~min}$ of UV irradiation for MIX 5 wt\% on montmorillonite containing $1 \mathrm{wt} \%$ of Mg-perchlorate. Legend: $\Delta_{\text {pre-irr }}=$ wavenumber shift with respect to the same peak pre-irradiation; $v=$ stretching vibrational mode; $\delta=$ bending vibrational mode.

From these data, AMP appears to be the most difficult molecule to detect in the NIR, because it does not absorb in the $8000-20000 \mathrm{~cm}^{-1}$ spectral range and presents only a few weak bands in the 2000-8000 $\mathrm{cm}^{-1}$ spectral range detectable mainly at $5 \mathrm{wt} \%$, although a very weak band at $4730 \mathrm{~cm}^{-1} \mathrm{can}$ still be detected at $1 \mathrm{wt} \%$. Based on DFT calculations at anharmonic level, we assigned this band to two strong combinations: $\mathrm{vOH}+\delta \mathrm{OH}_{\text {phosphate }}$ and $v_{\text {asym }} \mathrm{NH}_{2}+\delta \mathrm{C}_{8} \mathrm{H}, \delta_{\text {rock }} \mathrm{NH}_{2}$. Due to molecule-mineral interactions, this band undergoes a significant high-frequency shift of $90 \mathrm{~cm}^{-1}$ with the respect to the case of pure AMP in the solid state, which indicates that the amino group of the adenine moiety is mainly involved in the interactions with the mineral. The other detectable peaks in the region of $\mathrm{C}-\mathrm{H}$ stretching, instead, undergo less significant shifts, i.e. $20 \mathrm{~cm}^{-1}$ for the peak at $2965 \mathrm{~cm}^{-1}, 14 \mathrm{~cm}^{-1}$ for the peak at $2930 \mathrm{~cm}^{-1},-17 \mathrm{~cm}^{-1}$ for the peak at $2878 \mathrm{~cm}^{-1},-31 \mathrm{~cm}^{-1}$ for the peak at $2852 \mathrm{~cm}^{-1}$, and no shift for the peak at $2700 \mathrm{~cm}^{-1}$. In the presence of $1 \mathrm{wt} \%$ of magnesium perchlorate, we can observe some differences, i.e. the peaks at $2945 \mathrm{~cm}^{-1}$ and $2883 \mathrm{~cm}^{-1}$ which are at exactly the same wavenumber of pure AMP, and the peaks at 2930 and $2878 \mathrm{~cm}^{-1}$ which are not observable. Unfortunately, most of these peaks are too weak to evaluate intensity variations due to UV irradiation, but new features due to the formation of photoproducts are clearly observed at $3390,4070,4220$ and $4460 \mathrm{~cm}^{-1}$.

GLU adsorbed on montmorillonite presents remarkable red-shifts with respect to pure GLU in the solid state, of 240 and $230 \mathrm{~cm}^{-1}$ for the peaks of highest intensity at 6468 and $4870 \mathrm{~cm}^{-1}$, respectively, attributable to the overtone $2 v_{\text {asym }} \mathrm{NH}_{2}$ and the combination $v_{\text {asym }} \mathrm{NH}_{2}+\delta \mathrm{NH}_{2}$, which are the same in the presence of $1 \mathrm{wt} \%$ of magnesium perchlorate and indicate the involvement of the $\mathrm{NH}_{2}$ functional group in the interaction with the mineral. New features appear as consequence of UV irradiation, at 4075,3280 , and $2343 \mathrm{~cm}^{-1}$, indicative of the formation of photoproducts. 
PHE is the molecule with the most intense bands in the NIR when adsorbed on montmorillonite. Significantly intense bands detectable also at $1 \mathrm{wt} \%$ occur at: $5970 \mathrm{~cm}^{-1}$, attributable to the overtone

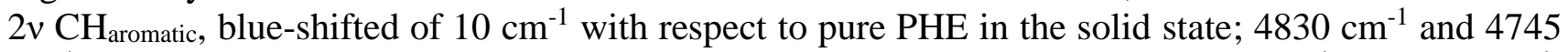
$\mathrm{cm}^{-1}$, attributable to the combinations $v$ ring $+v \mathrm{CH}_{\text {aromatic }}$, blue-shifted of $159 \mathrm{~cm}^{-1}$ and $108 \mathrm{~cm}^{-1}$, respectively; $4673 \mathrm{~cm}^{-1}$, attributable to $v$ ring $+v \mathrm{CH}_{\text {aromatic }}$, blue-shifted of $92 \mathrm{~cm}^{-1}$; and $4045 \mathrm{~cm}^{-1}$, attributable to the combination ring def $+v \mathrm{CH}_{\text {aromatic }}$, not shifted with respect to pure PHE in the solid state. Weaker bands can be detected also for the $0.1 \mathrm{wt} \%$ concentration at $3261 \mathrm{~cm}^{-1}$, attributable to the fundamental $\vee \mathrm{CH}_{\text {aromatic }}$, blue-shifted of $141 \mathrm{~cm}^{-1}$ with respect to pure PHE in the solid state, and $2928 \mathrm{~cm}^{-1}$, attributable to the fundamental $v_{\text {asym }} \mathrm{CH}_{2} / v \mathrm{CH}$, red-shifted of $42 \mathrm{~cm}^{-1}$ with respect to pure PHE in the solid state. These variations indicate involvement of the $\mathrm{C}-\mathrm{H}$ of the aromatic ring in the interaction with the mineral. In addition, in the case of 5 and $1 \mathrm{wt} \%$, a new band due to moleculemineral interactions is detectable at $6340 \mathrm{~cm}^{-1}$, indicative of chemisorption. The presence of $1 \mathrm{wt} \%$ of magnesium perchlorate does not seem to affect the NIR features, while UV irradiation causes intensity decreases for the bands at $5970 \mathrm{~cm}^{-1}$ (about 4\%), $4745 \mathrm{~cm}^{-1}$ (about 43\%), $2545 \mathrm{~cm}^{-1}$ (about 13\%), and $2455 \mathrm{~cm}^{-1}$ (about 35\%), along with the formation of a peak at $7140 \mathrm{~cm}^{-1}$ due to formation of photoproducts.

PHA adsorbed on montmorillonite is also clearly detectable in the NIR thanks to the band at $6000 \mathrm{~cm}^{-}$ , attributable to the overtone $2 \mathrm{vCH}$, red-shifted by $50 \mathrm{~cm}^{-1}$ with respect to pure PHA in the solid state when PHA is adsorbed on montmorillonite at $5 \mathrm{wt} \%$, which undergoes a further red-shift of $10 \mathrm{~cm}^{-1}$ at $1 \mathrm{wt} \%$, and the band at $4665 \mathrm{~cm}^{-1}$, attributable to the combination $v$ ring $+v \mathrm{CH}_{\text {aromatic }}$, whose red-shift with respect to pure PHA in the solid state goes from $14 \mathrm{~cm}^{-1}$ when PHA is adsorbed on montmorillonite at $5 \mathrm{wt} \%$ to $19 \mathrm{~cm}^{-1}$ at $1 \mathrm{wt} \%$ and 24 at $0.1 \mathrm{wt} \%$. Significant shifts with respect to pure PHA can be observed also for other weaker bands like the combination $\delta \mathrm{CH}_{\text {aromatic }}+v \mathrm{CH}_{\text {aromatic }}$ at 4617 $\mathrm{cm}^{-1}$ with a blue-frequency shift of $32 \mathrm{~cm}^{-1}$, the fundamental $\mathrm{vCH}$ at $3078 \mathrm{~cm}^{-1}$ with a red-shift of 10 $\mathrm{cm}^{-1}$, the combination $\delta \mathrm{OH}+v$ ring at $2905 \mathrm{~cm}^{-1}$ with a blue-shift of $23 \mathrm{~cm}^{-1}$, and the combination $\delta \mathrm{OH}+\mathrm{vOH}$ at $2814 \mathrm{~cm}^{-1}$ with a blue-shift of $44 \mathrm{~cm}^{-1}$. Also in this case, new bands due to moleculemineral interactions are observed, one at $8490 \mathrm{~cm}^{-1}$ at all concentrations, and another at $3505 \mathrm{~cm}^{-1}$ only detectable at $5 \mathrm{wt} \%$. In the case of PHA, many peaks are slightly different in the sample spiked with 1 wt $\%$ magnesium perchlorate: $4660 \mathrm{~cm}^{-1} \Delta_{\mathrm{PHA}}=-19 \mathrm{~cm}^{-1}, 4210 \mathrm{~cm}^{-1} \Delta_{\mathrm{PHA}}=-12 \mathrm{~cm}^{-1}, 4149 \mathrm{~cm}^{-1} \Delta_{\mathrm{PHA}}=-$ $7 \mathrm{~cm}^{-1}$, and $3069 \mathrm{~cm}^{-1} \Delta_{\mathrm{PHA}}=-19 \mathrm{~cm}^{-1}$. Other differences are the presence of the peak at $3940 \mathrm{~cm}^{-1}$ $\Delta \mathrm{PHA}=30 \mathrm{~cm}^{-1}$, which is not observable in the analogous sample without magnesium perchlorate, and the absence of the peaks at 2928 and $2858 \mathrm{~cm}^{-1}$, which are detectable in the analogous sample without magnesium perchlorate. The effects of UV irradiation are, instead, negligible.

The NIR spectrum of the mixture of molecules adsorbed on montmorillonite appears dominated by PHE's features. The main peaks of PHE adsorbed on montmorillonite can be detected with small shifts, i.e. $5978 \mathrm{~cm}^{-1}$ (blue-shifted of $8 \mathrm{~cm}^{-1}$ with respect to PHE adsorbed on montmorillonite), $4850 \mathrm{~cm}^{-1}$ (blue-shifted of $20 \mathrm{~cm}^{-1}$ with respect to PHE adsorbed on montmorillonite), $4750 \mathrm{~cm}^{-1}$ (blue-shifted of $5 \mathrm{~cm}^{-1}$ with respect to PHE adsorbed on montmorillonite), and $4670 \mathrm{~cm}^{-1}$ (red-shifted of $3 \mathrm{~cm}^{-1}$ with respect to PHE adsorbed on montmorillonite). Furthermore, the new peak at $6340 \mathrm{~cm}^{-1}$ due to molecule-mineral interactions is the same observed in the case of PHE adsorbed on montmorillonite. Effects of the presence of magnesium perchlorate are not evident, while UV irradiation causes redshifts of $10 \mathrm{~cm}^{-1}$ for the peaks at 4850 and $4750 \mathrm{~cm}^{-1}$, not observed in the case of PHE adsorbed on montmorillonite. The peak at $4740 \mathrm{~cm}^{-1}$ also undergoes an intensity decrease, as observed with PHE adsorbed on montmorillonite, but at a much lower extent (15\% vs. $43 \%$ ). Finally, UV irradiation causes the formation of the same photoproduct as in the case of PHE adsorbed on montmorillonite, as indicated by the appearance of the same band at $7140 \mathrm{~cm}^{-1}$. 
Regarding NIR features of montmorillonite, as seen in Table 2, they are not affected by molecular interactions, neither by the presence of $1 \mathrm{wt} \%$ of magnesium perchlorate. However, UV irradiation causes some changes that depend on the molecule adsorbed.

In the case of AMP, the peak of montmorillonite at $7063 \mathrm{~cm}^{-1}$, attributable to the overtone of the $\mathrm{Al}_{2} \mathrm{OH}$ stretching, undergoes a red-shift of $15 \mathrm{~cm}^{-1}$ as consequence of $70 \mathrm{~min}$ of UV irradiation and a $28 \%$ intensity decrease. The peak at $6830 \mathrm{~cm}^{-1}$, due to the overtone of the stretching of the water adsorbed on the mineral, decreases in intensity up to complete disappearance after $70 \mathrm{~min}$ of UV irradiation. The peak at $5244 \mathrm{~cm}^{-1}$, due to a combination of stretching and bending of adsorbed water, also undergoes a significant decrease in intensity of $53 \%$ in 70 min of UV irradiation.

In the case of GLU, the peak of montmorillonite at $7063 \mathrm{~cm}^{-1}$ does not undergo any red-shift as a consequence of 70 min of UV irradiation, but a similar $28 \%$ intensity decrease is observed. The peak at $6830 \mathrm{~cm}^{-1}$ undergoes a decrease in intensity of $86 \%$, similar to the case of AMP. The peak at 5244 $\mathrm{cm}^{-1}$ also undergoes a significant decrease in intensity of $56 \%$ in 70 min of UV irradiation.

In the case of PHE, similar to the case of AMP, the peak of montmorillonite at $7063 \mathrm{~cm}^{-1}$ undergoes a red-shift of $10 \mathrm{~cm}^{-1}$ as consequence of $70 \mathrm{~min}$ of UV irradiation and a $24 \%$ intensity decrease. The peak at $6830 \mathrm{~cm}^{-1}$ undergoes a decrease in intensity of $96 \%$ similarly to the case of AMP and GLU. The peak at $5244 \mathrm{~cm}^{-1}$ undergoes a red-shift of $8 \mathrm{~cm}^{-1}$ and a significant decrease in intensity of $61 \%$ in 70 min of UV irradiation, as observed also in the other cases. In contrast to the other examples, the peak at $4515 \mathrm{~cm}^{-1}$ undergoes a slight intensity decrease of $6 \%$ due to a combination of stretching and bending of the $\mathrm{OH}$ group.

For PHA, as for GLU, the montmorillonite peak at $7063 \mathrm{~cm}^{-1}$ does not undergo a red-shift as a consequence of 70 min of UV irradiation, but a similar $25 \%$ intensity decrease is observed. The peak at $6830 \mathrm{~cm}^{-1}$ displays a lower decrease in intensity with respect to the other cases (52\%). Similar to PHE, the peak at $5244 \mathrm{~cm}^{-1}$ undergoes a red-shift of $9 \mathrm{~cm}^{-1}$ and a significant decrease in intensity of $54 \%$ in 70 min of UV irradiation. As for PHE, the peak at $4515 \mathrm{~cm}^{-1}$ also undergoes a slight intensity decrease of $8 \%$.

In the case of the mixture, as observed for PHA and GLU, the montmorillonite peak at $7063 \mathrm{~cm}^{-1}$ does not undergo a red-shift as a consequence of $70 \mathrm{~min}$ of UV irradiation but we observe a $23 \%$ intensity decrease. As observed with PHA, the $6830 \mathrm{~cm}^{-1}$ peak shows a smaller decrease in intensity $(61 \%)$. Similar to PHE and PHA, the peak at $5244 \mathrm{~cm}^{-1}$ undergoes a red-shift of $4 \mathrm{~cm}^{-1}$ and a significant decrease in intensity of $47 \%$ in 70 min of UV irradiation. No variations of the peak at $4515 \mathrm{~cm}^{-1}$ are observed in this case.

\section{Discussion}

The NIR characterization of Mars soil analog samples obtained by doping montmorillonite (MONT) with the nucleic acid component adenosine 5'-monophosphate (AMP), the amino acids L-glutamic acid (GLU) and L-phenylalanine (PHE), and phthalic acid, which is a plausible precursor of the chlorohydrocarbons detected on Mars by the Curiosity rover, has shown that this spectroscopic technique is suitable for detection of these kinds of organic molecules when adsorbed on MONT (Steele et al., 2018). Indeed, some bands can be detected for all molecules adsorbed on MONT, with estimated detection limits of $\leq 250 \mathrm{ppm}$ for PHE, $\leq 1000 \mathrm{ppm}$ for PHA and GLU, and $\leq 50000 \mathrm{ppm}$ for AMP (despite a very weak band at $4730 \mathrm{~cm}^{-1}$ can be detected also at $1000 \mathrm{ppm}$ ). In the case of samples 
with an adsorbed mixture of all four molecules (MIX), PHE's adsorption features predominate, consistent with PHE being the molecule with the lowest detection limit.

We did not observe significant differences in the presence of $1 \mathrm{wt} \%$ magnesium perchlorate, except for MONTP+PHA, and to smaller extent MONTP+AMP, where discrepancies are within $10 \mathrm{~cm}^{-1}$. This finding suggests that such an amount of magnesium perchlorate does not interfere with moleculemineral interactions.

We did not observe significant frequency shifts at different organic concentrations, but only fewer and less intense bands with lower organic concentrations, as expected, except for PHA, which presents larger red-shifts at lower concentrations. Different molecular peak positions at different surface coverage can be explained considering that molecules may occupy different surface sites at different concentrations, which results in different spectroscopic features.

Very importantly, we observed significant frequency shifts with respect to pure molecules (even greater than $100 \mathrm{~cm}^{-1}$ ) for some vibrational modes of molecular functional groups involved in the interaction with the mineral and new features due to chemisorption in the case of PHE and PHA, while the mineral features were unaltered. In addition, in the case of samples obtained by adsorbing a mixture of all four molecules on montmorillonite, the bands of PHE detected were shifted with respect to the case of the samples with only PHE adsorbed on montmorillonite, indicating that molecules influence each other's adsorption, consequently affecting spectroscopic features. These results highlight the importance of establishing databases of spectroscopic features of molecule-mineral complexes because the features observed for organic molecules change when they are adsorbed on minerals; therefore, databases of spectroscopic features for pure molecules and pure minerals are not adequate for correct assignments.

Moreover, UV irradiation experiments show that at very short timescales both molecular and mineral NIR features are affected by UV radiation. Regarding molecular features, in most of the cases we do not observe significant intensity decreases, indicating that montmorillonite does not promote molecular degradation, except for the combination band $v$ ring $+v \mathrm{CH}_{\text {aromatic }}$ of $\mathrm{PHE}$ at $4745 \mathrm{~cm}^{-1}$ ( $43 \%$ of loss), which was limited to only $15 \%$ loss in the samples for which all four molecules adsorb as a mixture on montmorillonite. This result possibly indicates a photoprotective effect due to interactions among the different molecules. On the other hand, we observed the appearance of new features due to the formation of photoproducts in the case of AMP, PHE and GLU, whose nature is still to be determined. Regarding mineral features, the changes due to UV irradiation are particularly important both for the structural O-H groups of the mineral and the adsorbed water, whose bands undergo significant intensity decreases. Very interestingly, such changes depend on the specific molecule adsorbed. Indeed, in the case of AMP and PHE adsorbed on montmorillonite, we observed red-shifts of the overtone of the $\mathrm{Al}_{2} \mathrm{OH}$ stretching, whereas for PHE, PHA and MIX, we observed red-shifts of the combination band of stretching and bending of adsorbed water, indicating a weakening of the respective bonds as consequence of UV irradiation. In addition, the extent of intensity decrease of these bands is different for the different molecules adsorbed. These results indicate that molecule-mineral interactions influence the possible photochemical mechanisms induced by UV radiation.

\section{Conclusions}

This study reports changes of the NIR spectroscopic features due to molecule-mineral interactions, molecular concentration, presence of oxidants such as magnesium perchlorate, and UV irradiation, for molecules relevant in the context of life detection, such as adenosine 5'-monophosphate, L-glutamic 
acid, L-phenylalanine, and phthalic acid, adsorbed on montmorillonite, a clay mineral common on Mars.

We observed that molecule-mineral interactions and UV irradiation cause the most significant changes in NIR spectra.

Specifically, chemisorption determines frequency shifts even greater than $100 \mathrm{~cm}^{-1}$ with respect to pure molecules for the vibrational modes of molecular functional groups involved in the interaction with the mineral and the appearance of new features. Very importantly, molecule-mineral interactions strongly depend on many factors, including conditions of preparation of molecule-mineral complexes, specific properties of minerals and molecules, presence of multiple components in the system, and so on. Therefore, to interpret NIR features of martian samples, it is very important to prepare many analog samples obtained with various combinations of relevant molecules and minerals under conditions mimicking the martian environment and establish large libraries of NIR spectra to use as reference.

Based on this study and previous works (Fornaro et al., 2018c, and references therein; Schuerger et al., 2006, 2003), the effects of UV radiation on NIR features occur quite rapidly, showing both variations in intensities and frequencies of molecular and mineral bands, and the appearance of photoproduct marker bands. Such effects concern mostly surficial samples reached by UV radiation, although regolith-bound organics moved around by dust devils and aeolian erosion can be affected as well. Subsurface exploration is therefore necessary to investigate organics in their original form. In this regard, the ExoMars 2020 mission will offer a great opportunity to inspect the alteration state of organic matter as a function of depth up to $2 \mathrm{~m}$, providing also valuable information for interpreting Mars 2020 data acquired on more altered surficial samples.

This study highlights the importance of establishing custom databases of spectroscopic features for molecule-mineral complexes under martian-like conditions in order to assist interpretation of data collected by instruments based on NIR spectroscopy, such as SuperCam on board Mars 2020 space mission, ISEM, in situ and MicrOmega on board ExoMars 2020 space mission. To this end, such investigations provide important information on where to look for molecular spectroscopic features in NIR when molecules are embedded in plausible "martian" mineral matrices, along with assignments of molecular vibrational modes in the NIR spectral region, which are very scarce in the literature.

Furthermore, this work enables us to identify the molecules with the highest detection potential in the NIR when associated with specific minerals and, hence, select the best analog samples to be used for testbed analyses of flight instruments.

\section{Conflict of Interest}

The authors declare that the research was conducted in the absence of any commercial or financial relationships that could be construed as a potential conflict of interest.

\section{$7 \quad$ Author Contributions}

T.F. prepared and characterized the Mars soil analog samples, analysed all data and wrote the paper. J.B., G.P. and M.A.C. contributed to NIR characterization and UV irradiation experiments. M.B. performed DFT calculations. M.J. carried out mineral characterization. D.F. performed XRF and IRMS measurements. A.S. and R.H. mentored this work and contributed to paper revision. 


\section{$8 \quad$ Funding}

This research was supported by the Geophysical Laboratory of the Carnegie Institution of Washington and the Italian Space Agency (ASI) grant agreement ExoMars n. 2017-48-H.0. D.F. acknowledges support provided by the NASA awards NNX15AH77G and 80NSSC19K0559. MB acknowledges support from the National Natural Science Foundation of China (Grant No. 31870738).

\section{Acknowledgments}

The authors acknowledge Timothy Strobel of the Geophysical Laboratory of the Carnegie Institution of Washington for his scientific and technical assistance in performing XRD measurements.

\section{References}

Barone, V., 2005. Anharmonic Vibrational Properties by a Fully Automated Second-Order Perturbative Approach. J. Chem. Phys. 122, 14108.

Barone, V., Biczysko, M., Bloino, J., 2014. Fully anharmonic IR and Raman spectra of medium-size molecular systems: accuracy and interpretation. Phys. Chem. Chem. Phys. 16, 1759-1787.

Barone, V., Biczysko, M., Puzzarini, C., 2015. Quantum Chemistry Meets Spectroscopy for Astrochemistry: Increasing Complexity toward Prebiotic Molecules. Acc. Chem. Res. 48, 14131422.

Becke, A.D., 1993. Density-functional Thermochemistry. III. The Role of Exact Exchange. J. Chem. Phys. 98, 5648-5652.

Bibring, J.P., Hamm, V., Pilorget, C., Vago, J.L., 2017. The MicrOmega Investigation Onboard ExoMars. Astrobiology 17, 621-626.

Biczysko, M., Bloino, J., Puzzarini, C., 2018. Computational challenges in Astrochemistry. Wiley Interdiscip. Rev. Comput. Mol. Sci. 8, 1349.

BISHOP, J., MADEJOVÁ, J., KOMADEL, P., FRÖSCHL, H., 2002. The Influence of Structural Fe, $\mathrm{Al}$ and $\mathrm{Mg}$ on the Infrared $\mathrm{OH}$ Bands in Spectra of Dioctahedral Smectites. Clay Miner. 37, 607-616.

Bloino, J., 2015. A VPT2 Route to Near-Infrared Spectroscopy: The Role of Mechanical and Electrical Anharmonicity. J. Phys. Chem. A 119, 5269-5287.

Bloino, J., Baiardi, A., Biczysko, M., 2016. Aiming at an accurate prediction of vibrational and electronic spectra for medium-to-large molecules: An overview. Int. J. Quantum Chem. 116, 1543-1574.

Bloino, J., Biczysko, M., Barone, V., 2015. Anharmonic Effects on Vibrational Spectra Intensities: 
Infrared, Raman, Vibrational Circular Dichroism, and Raman Optical Activity. J. Phys. Chem. A 119, 11862-11874.

Clark, B.C., Kounaves, S.P., 2016. Evidence for the distribution of perchlorates on Mars. Int. J. Astrobiol. 15, 311-318.

Clark, R.N., Curchin, J.M., Hoefen, T.M., Swayze, G.A., 2009. Reflectance spectroscopy of organic compounds: 1. Alkanes. J. Geophys. Res. Planets 114, E03001.

De Sanctis, M.C., Altieri, F., Ammannito, E., Biondi, D., De Angelis, S., Meini, M., Mondello, G., Novi, S., Paolinetti, R., Soldani, M., Mugnuolo, R., Pirrotta, S., Vago, J.L., 2017. Ma-MISS on ExoMars: Mineralogical Characterization of the Martian Subsurface. Astrobiology 17, 612-620.

Des Marais, D.J., Nuth, J.A., Allamandola, L.J., Boss, A.P., Farmer, J.D., Hoehler, T.M., Jakosky, B.M., Meadows, V.S., Pohorille, A., Runnegar, B., Spormann, A.M., 2008. The NASA Astrobiology Roadmap. Astrobiology 8, 715-730.

Ehrlich, S., Moellmann, J., Reckien, W., Bredow, T., Grimme, S., 2011. System-dependent dispersion coefficients for the DFT-D3 treatment of adsorption processes on ionic surfaces. ChemPhysChem 12, 3414-3420.

Eigenbrode, J.L., Summons, R.E., Steele, A., Freissinet, C., Millan, M., Navarro-gonzález, R., Sutter, B., Mcadam, A.C., Conrad, P.G., Hurowitz, J.A., Grotzinger, J.P., Gupta, S., 2018. Organic matter preserved in 3-billion-year-old mudstones at Gale crater, Mars. Science 360, 1096-1101.

Fornaro, T., Biczysko, M., Bloino, J., Barone, V., 2016. Reliable Vibrational Wavenumbers for C=O and N-H Stretchings of Isolated and Hydrogen-Bonded Nucleic Acid Bases. Phys. Chem. Chem. Phys. 18, 8479-8490.

Fornaro, T., Biczysko, M., Monti, S., Barone, V., 2014. Dispersion Corrected DFT Approaches for Anharmonic Vibrational Frequency Calculations: Nucleobases and their Dimers. Phys. Chem. Chem. Phys. 16, 10112-10128.

Fornaro, T., Boosman, A., Brucato, J.R., ten Kate, I.L., Siljeström, S., Poggiali, G., Steele, A., Hazen, R.M., 2018a. UV irradiation of biomarkers adsorbed on minerals under Martian-like conditions: Hints for life detection on Mars. Icarus 313, 38-60.

Fornaro, T., Brucato, J.R., Branciamore, S., Pucci, A., 2013a. Adsorption of Nucleic Acid Bases on Magnesium Oxide (MgO). Int. J. Astrobiol. 12, 78-86.

Fornaro, T., Brucato, J.R., Feuillie, C., Sverjensky, D.A., Hazen, R.M., Brunetto, R., D’Amore, M., Barone, V., 2018b. Binding of Nucleic Acid Components to the Serpentinite-hosted Hydrothermal Mineral Brucite. Astrobiology 18, 989-1007.

Fornaro, T., Brucato, J.R., Pace, E., Cestelli-Guidi, M., Branciamore, S., Pucci, A., 2013b. Infrared Spectral Investigations of UV Irradiated Nucleobases Adsorbed on Mineral Surfaces. Icarus 226, 1068-1085.

Fornaro, T., Burini, D., Biczysko, M., Barone, V., 2015a. Hydrogen-Bonding Effects on Infrared Spectra from Anharmonic Computations: Uracil-Water Complexes and Uracil Dimers. J. Phys. 
Chem. A 119, 4224-4236.

Fornaro, T., Carnimeo, I., Biczysko, M., 2015b. Toward Feasible and Comprehensive Computational Protocol for Simulation of the Spectroscopic Properties of Large Molecular Systems: The Anharmonic Infrared Spectrum of Uracil in the Solid State by the Reduced Dimensionality/Hybrid VPT2 Approach. J. Phys. Chem. A 119, 5313-5326.

Fornaro, T., Steele, A., Brucato, J.R., 2018c. Catalytic/Protective Properties of Martian Minerals and Implications for Possible Origin of Life on Mars. Life 8, 1-41.

Foustoukos, D.I., Stern, J.C., 2012. Oxidation pathways for formic acid under low temperature hydrothermal conditions: Implications for the chemical and isotopic evolution of organics on Mars. Geochim. Cosmochim. Acta 76, 14-28.

Freissinet, C., Glavin, D.P., Mahaffy, P.R., Miller, K.E., Eigenbrode, J.L., Summons, R.E., Brunner, A.E., Buch, A., Szopa, C., Archer, P.D., Franz, H.B., Atreya, S.K., Brinckerhoff, W.B., Cabane, M., Coll, P., Conrad, P.G., Marais, D.J. Des, Dworkin, J.P., Fairén, A.G., François, P., Grotzinger, J.P., Kashyap, S., Kate, I.L., Leshin, L.A., Malespin, C.A., Martin, M.G., Mcadam, A.C., Ming, D.W., Pavlov, A.A., Prats, B.D., Squyres, S.W., Steele, A., Stern, J.C., Sumner, D.Y., Sutter, B., Zorzano, M., 2015. Organic molecules in the sheepbed mudstone, gale crater, mars. J. Geophys. Res. Planets 120, 495-514.

Frisch, M.J., Trucks, G.W., Schlegel, H. B. Scuseria, G.E., Robb, M. A. Cheeseman, J. R. Scalmani, G., Barone, V., Petersson, G. A. Nakatsuji, H., Li, X., Caricato, M., Marenich, A. V., Bloino, J., Janesko, B.G., Gomperts, R., Mennucci, B., Hratchian, H.P., Ortiz, J. V., Izmaylov, A.F., Sonnenberg, J.L., Williams-Young, D., Ding, F., Lipparini, F., Egidi, F., Goings, J., Peng, B., Petrone, A., Henderson, T., Ranasinghe, D. Zakrzewski, V.G., Gao, J., Rega, N., Zheng, G., Liang, W., Hada, M., Ehara, M., Toyota, K., Fukuda, R., Hasegawa, J., Ishida, M., Nakajima, T., Honda, Y., Kitao, O., Nakai, H., Vreven, T., Throssell, K., Montgomery, J. A., J., Peralta, J.E., Ogliaro, F., Bearpark, M.J., Heyd, J.J., Brothers, E.N., Kudin, K.N., Staroverov, V.N., Keith, T.A., Kobayashi, R., Normand, J., Raghavachari, K., Rendell, A.P., Burant, J.C., Iyengar, S.S., Tomasi, J., Cossi, M., Millam, J.M., Klene, M., Adamo, C., Cammi, R., Ochterski, J.W., Martin, R.L., Morokuma, K., Farkas, O., Foresman, J.B., Fox, D.J., 2016. Gaussian 16, Revision C.01.

Gerakines, P.A., Hudson, R.L., Moore, M.H., Bell, J.-L., 2012. In situ measurements of the radiation stability of amino acids at 15-140 K. Icarus 220, 647-659.

Glavin, D.P., Freissinet, C., Miller, K.E., Eigenbrode, J.L., Brunner, A.E., Buch, A., Sutter, B., Archer, P.D., Atreya, S.K., Brinckerhoff, W.B., Cabane, M., Coll, P., Conrad, P.G., Coscia, D., Dworkin, J.P., Franz, H.B., Grotzinger, J.P., Leshin, L.A., Martin, M.G., McKay, C., Ming, D.W., Navarro-Gonz??lez, R., Pavlov, A., Steele, A., Summons, R.E., Szopa, C., Teinturier, S., Mahaffy, P.R., 2013. Evidence for perchlorates and the origin of chlorinated hydrocarbons detected by SAM at the Rocknest aeolian deposit in Gale Crater. J. Geophys. Res. E Planets 118, 1955-1973.

Grimme, S., Antony, J., Ehrlich, S., Krieg, H., 2010. A consistent and accurate ab initio parametrization of density functional dispersion correction (DFT-D) for the 94 elements H-Pu. J. Chem. Phys. 132, 154104. 
Grimme, S., Ehrlich, S., Goerigk, L., 2011. Effect of the damping function in dispersion corrected density functional theory. J. Comput. Chem. 32, 1456-1465.

Hassler, D.M., Zeitlin, C., Wimmer-schweingruber, R.F., Ehresmann, B., Rafkin, S., Eigenbrode, J.L., Brinza, D.E., Weigle, G., Böttcher, S., Böhm, E., Burmeister, S., Guo, J., Köhler, J., Martin, C., Reitz, G., Cucinotta, F.A., Kim, M., Grinspoon, D., Bullock, M.A., Posner, A., Gómez-elvira, J., Vasavada, A., Grotzinger, J.P., Team, M.S.L.S., 2014. Mars ' Surface Radiation Environment measured with the Mars science laboratory's curiosity rover. Science $343,1244797$.

Korablev, O.I., Dobrolensky, Y., Evdokimova, N., Fedorova, A.A., Kuzmin, R.O., Mantsevich, S.N., Cloutis, E.A., Carter, J., Poulet, F., Flahaut, J., Griffiths, A., Gunn, M., Schmitz, N., MartínTorres, J., Zorzano, M.P., Rodionov, D.S., Vago, J.L., Stepanov, A. V., Titov, A.Y., Vyazovetsky, N.A., Trokhimovskiy, A.Y., Sapgir, A.G., Kalinnikov, Y.K., Ivanov, Y.S., Shapkin, A.A., Ivanov, A.Y., 2017. Infrared Spectrometer for ExoMars: A Mast-Mounted Instrument for the Rover. Astrobiology 17(6-7), 542-564.

Kounaves, S.P., Carrier, B.L., O’Neil, G.D., Stroble, S.T., Claire, M.W., 2014. Evidence of martian perchlorate, chlorate, and nitrate in Mars meteorite EETA79001: Implications for oxidants and organics. Icarus 229, 206-213.

Lasne, J., Noblet, A., Szopa, C., Navarro-González, R., Cabane, M., Poch, O., Stalport, F., François, P., Atreya, S.K., Coll, P., 2016. Oxidants at the Surface of Mars: A Review in Light of Recent Exploration Results. Astrobiology 16, 977-996.

Licari, D., Baiardi, A., Biczysko, M., Egidi, F., Latouche, C., Barone, V., 2015. Implementation of a Graphical User Interface for the Virtual Multifrequency Spectrometer: The VMS-Draw Tool. J. Comp. Chem. 36, 321-334.

Madejová, J., 2003. FTIR techniques in clay mineral studies. Vib. Spectrosc. 31(1), 1-10.

Madejová, J., Pálková, H., Komadel, P., 2006. Behaviour of Li+ and Cu2+ in heated montmorillonite: Evidence from far-, mid-, and near-IR regions. Vib. Spectrosc. 40, 80-88.

Pavlov, A.K., Blinov, A.V., Konstantinov, A.N., 2002. Sterilization of Martian surface by cosmic radiation. Planet. Space Sci. 50, 669-673.

Schuerger, A.C., Mancinelli, R.L., Kern, R.G., Rothschild, L.J., McKay, C.P., 2003. Survival of endospores of Bacillus subtilis on spacecraft surfaces under simulated martian environments:: implications for the forward contamination of Mars. Icarus 165, 253-276.

Schuerger, A.C., Richards, J.T., Newcombe, D.A., Venkateswaran, K., 2006. Rapid inactivation of seven Bacillus spp. under simulated Mars UV irradiation. Icarus 181, 52-62.

Steele, A., Benning, L.G., Wirth, R., Siljeström, S., Fries, M.D., Hauri, E., Conrad, P.G., Rogers, K., Eigenbrode, J., Schreiber, A., Needham, A., Wang, J.H., McCubbin, F.M., Kilcoyne, D., Blanco, J.D.R., 2018. Organic synthesis on Mars by electrochemical reduction of CO2. Sci. Adv. 4, eaat5118.

Steele, A., McCubbin, F.M., Fries, M., Kater, L., Boctor, N.Z., Fogel, M.L., Conrad, P.G., 
Glamoclija, M., Spencer, M., Morrow, A.L., Hammond, M.R., Zare, R.N., Vicenzi, E.P., Siljeström, S., Bowden, R., Herd, C.D.K., Mysen, B.O., Shirey, S.B., Amundsen, H.E.F., Treiman, A.H., Bullock, E.S., Jull, A.J.T., 2012. A reduced organic carbon component in martian basalts. Science 337, 212-215.

ten Kate, I.L., 2010. Organics on Mars? Astrobiology 10, 589-603.

Vago, J.L., Westall, F., Coates, A.J., Jaumann, R., Korablev, O., Ciarletti, V., Mitrofanov, I., Josset, J.L., De Sanctis, M.C., Bibring, J.P., Rull, F., Goesmann, F., Steininger, H., Goetz, W., Brinckerhoff, W., Szopa, C., Raulin, F., Edwards, H.G.M., Whyte, L.G., Fairén, A.G., Bridges, J., Hauber, E., Ori, G.G., Werner, S., Loizeau, D., Kuzmin, R.O., Williams, R.M.E., Flahaut, J., Forget, F., Rodionov, D., Svedhem, H., Sefton-Nash, E., Kminek, G., Lorenzoni, L., Joudrier, L., Mikhailov, V., Zashchirinskiy, A., Alexashkin, S., Calantropio, F., Merlo, A., Poulakis, P., Witasse, O., Bayle, O., Bayón, S., Meierhenrich, U., Carter, J., García-Ruiz, J.M., Baglioni, P., Haldemann, A., Ball, A.J., Debus, A., Lindner, R., Haessig, F., Monteiro, D., Trautner, R., Voland, C., Rebeyre, P., Goulty, D., Didot, F., Durrant, S., Zekri, E., Koschny, D., Toni, A., Visentin, G., Zwick, M., Van Winnendael, M., Azkarate, M., Carreau, C., 2017. Habitability on Early Mars and the Search for Biosignatures with the ExoMars Rover. Astrobiology 17(6-7), 471-510.

Walter, N., Westall, F., Horneck, G., Grenfell, J.L., Martin, W.F., Gomez, F., Leuko, S., Lee, N., Onofri, S., Tsiganis, K., Saladino, R., Harrison, J., Pilat-lohinger, E., Palomba, E., Rull, F., Muller, C., Strazzulla, G., Brucato, J.R., Rettberg, P., Capria, M.T., 2016. AstRoMap European Astrobiology Roadmap. Astrobiology 16, 201-243.

Wiens, R.C., Maurice, S., Rull Perez, F., Team, and the S., 2017. The SuperCam remote sensing instrument suite for the Mars 2020 rover mission: A preview. Spectroscopy 32, LA-UR-1726876.

Williford, K.H., Farley, K.A., Stack, K.M., Allwood, A.C., Beaty, D., Beegle, L.W., Bhartia, R., Brown, A.J., de la Torre Juarez, M., Hamran, S.-E., Hecht, M.H., Hurowitz, J.A., RodriguezManfredi, J.A., Maurice, S., Milkovich, S., Wiens, R.C., 2018. The NASA Mars 2020 Rover Mission and the Search for Extraterrestrial Life, in: From Habitability to Life on Mars. Elsevier, pp. 275-308.

\section{Supplementary Material}

Supplementary Material is available online. 